\title{
Cleavage of the Vesicular GABA Transporter under Excitotoxic Conditions Is Followed by Accumulation of the Truncated Transporter in Nonsynaptic Sites
}

\author{
João R. Gomes, ${ }^{1,2}$ Andrea C. Lobo, ${ }^{1,2}$ Carlos V. Melo, ${ }^{1}$ Ana R. Inácio, ${ }^{4}$ Jiro Takano, ${ }^{5}$ Nobuhisa Iwata, ${ }^{5}$ Takaomi C. Saido, ${ }^{5}$ \\ Luís P. de Almeida, ${ }^{1,3}$ Tadeusz Wieloch, ${ }^{4}$ and Carlos B. Duarte ${ }^{1,2}$ \\ ${ }^{1}$ Center for Neuroscience and Cell Biology, ${ }^{2}$ Department of Life Sciences, and ${ }^{3}$ Faculty of Pharmacy, University of Coimbra, $3004-517$ Coimbra, Portugal, \\ ${ }^{4}$ Wallenberg Neuroscience Center, Lund University, 22184 Lund, Sweden, and ${ }^{5}$ RIKEN Brain Science Institute, Hirosawa, Wako-shi, Saitama, 351-0198, \\ Japan
}

GABA is the major inhibitory neurotransmitter in the CNS and changes in GABAergic neurotransmission affect the overall activity of neuronal networks. The uptake of GABA into synaptic vesicles is mediated by the vesicular GABA transporter (VGAT), and changes in the expression of the transporter directly regulate neurotransmitter release. In this work we investigated the changes in VGAT protein levels during ischemia and in excitotoxic conditions, which may affect the demise process. We found that VGAT is cleaved by calpains following excitotoxic stimulation of hippocampal neurons with glutamate, giving rise to a stable truncated cleavage product (tVGAT). VGAT cleavage was also observed after transient middle cerebral artery occlusion in mice, a cerebral ischemia model, and following intrahippocampal injection of kainate, but no effect was observed in transgenic mice overexpressing calpastatin, a calpain inhibitor. Incubation of isolated cerebrocortical synaptic vesicles with recombinant calpain also induced the cleavage of VGAT and formation of stable tVGAT. Immunoblot experiments using antibodies targeting different regions of VGAT and N-terminal sequencing analysis showed that calpain cleaves the transporter in the N-terminal region, at amino acids 52 and 60. Immunocytochemistry of GABAergic striatal neurons expressing GFP fusion proteins with the full-length VGAT or tVGAT showed that cleavage of the transporter induces a loss of synaptic delivery, leading to a homogeneous distribution of the protein along neurites. Our results show that excitotoxicity downregulates full-length VGAT, with a concomitant generation of tVGAT, which is likely to affect GABAergic neurotransmission and may influence cell death during ischemia.

\section{Introduction}

Glutamate is the major excitatory neurotransmitter in the CNS and together with GABA, the major inhibitory neurotransmitter, controls the activity of neuronal networks. Excitotoxicity mediated by overactivation of glutamate receptors plays a key role in neuronal death characteristic of different disorders of the nervous system, including ischemia, epilepsy, and neurodegenerative diseases (Szydlowska and Tymianski, 2010). The research in cerebral ischemia and excitotoxic neuronal damage has been mainly focused on the excitatory mediators and much less is known regarding the changes in GABAergic activity (SchwartzBloom and Sah, 2001). The release of GABA in the ischemic brain and the consequent activation of $\mathrm{GABA}_{\mathrm{A}}$ receptors may be neuroprotective through reduction of membrane depolarization. However, $\mathrm{Cl}^{-}$entry through $\mathrm{GABA}_{\mathrm{A}}$ receptors in association with

Received July 8, 2010; revised Jan. 8, 2011; accepted Feb. 1, 2011.

This work was supported by Fundação para a Ciência e a Tecnologia (FCT) and Fundo Europeu de Desenvolvimento Regional (FEDER), Portugal (PTDC/SAU-NEU/65846/2006). João R. Gomes and Andrea Lobo were supported by FCT, Portugal. We thank Elisabete Carvalho for assistance in the preparation of cell cultures and Mário Armelão for developing the Excel datasheet used to prepare Figure $7 C$.

Correspondence should be addressed to Carlos B. Duarte, Center for Neuroscience and Cell Biology, Department of Life Sciences, University of Coimbra, 3004-517 Coimbra, Portugal. E-mail: cbduarte@ci.uc.pt.

DOI:10.1523/JNEUROSCI.3541-10.2011

Copyright $\odot 2011$ the authors $\quad 0270-6474 / 11 / 314622-14 \$ 15.00 / 0$ overactivation of glutamate receptors may further increase the influx of water and cell swelling. The former mechanisms may be dominant since neuroprotective strategies to increase GABAergic neurotransmission, targeting both sides of the synapse, have been tested, and some of them were found to be quite efficacious in animal models of ischemia (Schwartz-Bloom and Sah, 2001).

The impairment of GABAergic synaptic transmission in brain ischemia is partly due to a downregulation of synaptic $\mathrm{GABA}_{\mathrm{A}}$ receptors, which may contribute to the ongoing neuronal excitability and possibly to neuronal death (Schwartz-Bloom and Sah, 2001). Furthermore, exposure of hippocampal slices to oxygenand glucose-deprivation was shown to induce an early release of GABA by exocytosis, followed by a delayed phase of neurotransmitter release mediated by reversal of the plasma membrane transporter (Allen et al., 2004). However, few studies have addressed the mechanisms underlying the presynaptic changes in GABAergic synapses. Much evidence has been gathered showing that the vesicular neurotransmitter transporters can influence the neural transmission, and changes in expression of the vesicular transporters have been shown to alter the exocytosis of amino acid neurotransmitters (Wilson et al., 2005; Erickson et al., 2006; Edwards, 2007; Wu et al., 2007; Lima Rde et al., 2010). Therefore, putative changes in the levels of vesicular GABA 
transporter (VGAT) in the ischemic brain may influence the release of GABA and therefore the balance between excitatory and inhibitory activity. In a recent work, the upregulation of VGLUT 1 was correlated with an increase in glutamatergic transmission, contributing to an increase in extracellular glutamate levels and hyperexcitability in patients with temporal lobe epilepsy (van der Hel et al., 2009).

Calpains are cysteine proteases involved in ischemic/excitotoxic cell death and in several chronic neurodegenerative conditions (Bevers and Neumar, 2008; Vosler et al., 2008). Under normal physiological conditions the activation of calpains is tightly regulated and plays a key role in the cleavage of selected protein targets (Liu et al., 2008). Activation of these proteases due to a $\left[\mathrm{Ca}^{2+}\right]_{\mathrm{i}}$ overload under excitotoxic conditions cleaves key synaptic proteins in glutamatergic synapses, including ionotropic (AMPA and NMDA receptor subunits) and metabotropic glutamate receptors (Xu et al., 2007; Yuen et al., 2007; Gascón et al., 2008), and postsynaptic scaffold proteins (Jourdi et al., 2005), but little information is available regarding the effect of calpains on GABAergic synapses. In the present study we evaluated the changes in VGAT protein levels and cellular distribution in pathological conditions, including excitotoxicity, brain ischemia, and following status epilepticus. The results show that VGAT is cleaved into a new stable truncated form that is not targeted to synapses, which is likely to affect GABAergic synaptic transmission.

\section{Materials and Methods}

\section{Primary neuronal cultures}

Cultures of rat hippocampal neurons were prepared from embryonic day 18 (E18) Wistar rat embryos as described previously (Almeida et al., 2005; Caldeira et al., 2007). Cortical and striatal neurons were cultured using the same procedures, from E15-16 Wistar rat embryos. Neuronal cultures were maintained in serum-free Neurobasal medium (Invitrogen), supplemented with B27 (Invitrogen), glutamate (Sigma, $25 \mu \mathrm{M}$ ), glutamine (Sigma, $0.5 \mathrm{~mm}$ ), and gentamicin (Invitrogen, $0.12 \mathrm{mg} / \mathrm{ml}$ ). Striatal and cortical cultures were maintained in the absence of glutamate. The cells were kept at $37^{\circ} \mathrm{C}$ in a humidified incubator with $5 \%$ $\mathrm{CO}_{2} / 95 \%$ air, for $7 \mathrm{~d}$ (hippocampal cultures) or $14-15 \mathrm{~d}$ (cortical and striatum cultures). Cells were cultured at a density of $90000 \mathrm{cells} / \mathrm{cm}^{2}$ or $80000 \mathrm{cells} / \mathrm{cm}^{2}$ on poly-D-lysine-coated (Sigma) six-well microplates (MW6) (for Western blot and real-time PCR experiments) or glass coverslips (for immunocytochemistry studies), respectively.

\section{PC12 cell line}

Pheochromocytoma PC12 cells were cultured in DMEM/ F12 (1:1) (Invitrogen), supplemented with $\mathrm{NaHCO}_{3}, \mathrm{pH} 7.2,5 \%$ fetal bovine serum (Invitrogen), 10\% horse serum (Invitrogen), and 1\% penicillin/streptomycin (Sigma). Cells were diluted every $2-3 \mathrm{~d}$ after achieving $80-90 \%$ confluency.

\section{Western blot}

Hippocampal, cortical, and striatal neuron cultures were washed twice with ice-cold PBS and once more with PBS buffer supplemented with 1 mM DTT and a mixture of protease inhibitors (0.1 mM PMSF, CLAP: 1 $\mu \mathrm{g} / \mathrm{ml}$ chymostatin, $1 \mu \mathrm{g} / \mathrm{ml}$ leupeptin, $1 \mu \mathrm{g} / \mathrm{ml}$ antipain, $1 \mu \mathrm{g} / \mathrm{ml}$ pepstatin; Sigma). The cells were then lysed with RIPA (150 mM NaCl, $50 \mathrm{~mm}$ Tris-HCl, pH 7.4, 5 mm EGTA, $1 \%$ Triton, $0.5 \%$ DOC, and $0.1 \%$ SDS at a final $\mathrm{pH}$ 7.5) supplemented with the mixture of protease inhibitors. After centrifugation at $16,100 \times g$ for $10 \mathrm{~min}$, protein in the supernatants was quantified using the BCA method, and the samples were denaturated with $2 \times$ concentrated denaturating buffer ( $125 \mathrm{~mm}$ Tris, $\mathrm{pH} 6.8,100 \mathrm{~mm}$ glycine, 4\% SDS, $200 \mathrm{~mm}$ DTT, $40 \%$ glycerol, 3 mm sodium orthovanadate, and $0.01 \%$ bromophenol blue). Extracts used for VGAT analysis were not subjected to a boiling step because it leads to VGAT aggregation.

Protein samples were separated by SDS-PAGE, in $12 \%$ polyacrylamide gels, transferred to polyvinylidene fluoride (PVDF) membranes (Milli- pore), and immunoblotted, as described previously (Caldeira et al., 2007). Blots were incubated with primary antibodies (overnight at $4^{\circ} \mathrm{C}$ ), washed, and exposed to alkaline phosphatase-conjugated secondary antibodies [1:20,000 dilution for anti-rabbit IgG and 1:10,000 dilution for mouse IgG (GE Healthcare); $1 \mathrm{~h}$ at room temperature]. Alkaline phosphatase activity was visualized by enhanced chemifluorescence on the Storm 860 gel and blot imaging system and quantified using the ImageQuant program (GE Healthcare). The following primary antibodies were used: anti-VGAT (1:2000, Ab: 75-87 aa; Synaptic Systems), antiVGAT (1:1000, Ab: 1-20 aa; Sigma), anti-VGAT (1:500, Ab: 500-525 aa; Millipore), anti-NR1 (1:200, Millipore), anti-human calpastatin (1:5000, Takara), and anti-GFP (1:2000, Abcam). The anti-synaptophysin (1: 10,000 , Synaptic Systems) antibody was used as loading control.

In control experiments the specificity of the anti-VGAT antibody (amino acids $75-87 ; 1: 2000$ ) was tested after preabsorbing the antibody with the peptide used for immunization $(1 \mu \mathrm{g} / \mathrm{ml}$; Synaptic Systems). The preadsorption was performed overnight at $4^{\circ} \mathrm{C}$ before incubation with the blotting membrane.

\section{Immunocytochemistry}

Cells were fixed in $4 \%$ sucrose/paraformaldehyde and permeabilized with $0.3 \%$ Triton X-100 in PBS. The neurons were then incubated with $0.2 \%$ gelatin (Sigma) in PBS $+0.1 \%$ Tween 20 , for $1 \mathrm{~h}$ at $37^{\circ} \mathrm{C}$, to block nonspecific staining, and incubated with primary antibodies, overnight at $4^{\circ} \mathrm{C}$. The cells were then washed five times with PBS $+0.1 \%$ Tween + $0.1 \%$ gelatin and incubated with the appropriate secondary antibodies, for $1 \mathrm{~h}$ at $37^{\circ} \mathrm{C}$. The coverslips were mounted in a fluorescent mounting medium (DAKO), and imaging was performed on a Zeiss LSM510 confocal microscope, using a $63 \times$ oil objective. The primary antibodies used were anti-VGAT (1:500, Ab: 75-87 aa; Synaptic Systems), anti-GABA (1:200, Abcam), and anti-synaptophysin (1:200, Sigma). The secondary antibodies used were Alexa Fluor 488, 594, 647, and Texas Red (Invitrogen). The fluorescent dye Hoechst 33342 (Sigma, $0.5 \mu \mathrm{g} / \mathrm{ml}$ ) was used to stain nuclei.

\section{$m R N A$ semiquantification through real-time PCR}

Total RNA was extracted from $7 \mathrm{~d}$ in vitro (DIV) cultured hippocampal neurons using TRIzol Reagent (Invitrogen), as described previously (Santos and Duarte, 2008), and the RNA quality and integrity was assessed using the Experion automated gel-electrophoresis system (BioRad), as described previously (Santos and Duarte, 2008). Samples showing RNA degradation or contamination by DNA were discarded. RNA concentration was determined using the fluorescent dye RiboGreen (Invitrogen-Molecular Probes) or NanoDrop 1000 (Thermo Scientific). The samples were aliquoted and stored at $-80^{\circ} \mathrm{C}$ until further use. cDNA synthesis was performed using $2 \mu \mathrm{g}$ of total RNA and the AMV reverse transcriptase (10 U; Roche), as described previously (Santos and Duarte, 2008). Samples were stored at $-80^{\circ} \mathrm{C}$ until further use.

Primers for real-time PCR were designed using the "Beacon Designer 7" software (Premier Biosoft International) as described previously (Santos and Duarte, 2008). The primers (Fisher Scientific) used for VGAT were as follows: forward, 5'GCCGTGTCCAAGTTCAGTC3' and reverse, 5'AGAGACAGTAGGCGATGACC3'. Gapdh was used as reference gene with the following primers: forward, 5'CTCCCATTCCTCCACCTTTG3' and reverse, 5'TGTAGCCATATTCATTGTCATACC3'. The annealing temperature was $55^{\circ} \mathrm{C}$.

For gene expression analysis, $2 \mu \mathrm{l}$ of 1:100 diluted cDNA was added to $10 \mu \mathrm{l}$ of $2 \times$ SYBR Green Master Mix (Bio-Rad), and the final concentration of each primer was $250 \mathrm{~nm}$ in $20 \mu \mathrm{l}$ total volume. The thermocycling reaction was initiated with activation of the TaqDNA Polymerase by heating at $95^{\circ} \mathrm{C}$ during $30 \mathrm{~s}$, followed by 55 cycles of a $10 \mathrm{~s}$ denaturation step at $95^{\circ} \mathrm{C}$, a $30 \mathrm{~s}$ annealing and a $30 \mathrm{~s}$ elongation step at $72^{\circ} \mathrm{C}$. The fluorescence was measured after the extension step, using the iQ5 Multicolor Real-Time PCR Detection System (Bio-Rad). After the thermocycling reaction, the melting step was performed with slow heating, starting at $55^{\circ} \mathrm{C}$ and with a rate of $0.5^{\circ} \mathrm{C}$ per $10 \mathrm{~s}$, up to $95^{\circ} \mathrm{C}$, with continuous measurement of fluorescence.

Data analysis was performed using Pfaffl method for efficiency correction (Pfaffl, 2001). The results were normalized with Gapdh as internal 
reference gene because it showed a stable expression in hippocampal neurons stimulated with glutamate.

\section{DNA constructs}

The rat full-length cDNA of VGAT was kindly provided by S. Takamori (Tokyo Medical and Dental University, Tokyo, Japan) (Takamori et al., 2000). The amplified fragment was digested by BamHI and XbaI (New England Biolabs) and purified by gel electrophoresis before subcloning into pcDNA3.1 (Invitrogen) at BamHI/XbaI sites.

Plasmids encoding truncated VGAT lacking amino acids 2-51 or 2-59

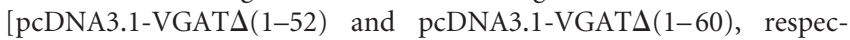
tively] were generated by site-directed mutagenesis (STRATAGENE). Both truncated proteins have amino acid 1 before the amino acids that correspond to the cleavage site, to ensure the translation of the protein in the cells.

The plasmid encoding the VGAT-GFP fusion protein was generated by molecular cloning. The cDNA of VGAT was fused into the green fluorescent protein (GFP) gene in pEGFP-N1 vector (BD Biosciences Clontech) through KpnI and AgeI sites, using the primers: forward, 5' CGG GGTACC ATGGCCACCCTGCTCCGCAG 3' and reverse, 5' CGG ACCGGT GA GTCCTCTGCGTTGGTTCGGTA $3^{\prime}$. The forward primer has the following: 3 nucleotides at the beginning (CGG) to improve KpnI cleavage (close to the end of DNA fragments), the KpnI cleavage Site (GGTACC), and then the starting codon ATG followed by additional nucleotides of VGAT cDNA. The reverse primer has the following: the same 3 nucleotides at the beginning (CGG) to improve AgeI cleavage, the AgeI cleavage site (ACCGGT), two nucleotides (GA) so that GFP stays in frame, the stop codon of VGAT is removed, and then the cDNA of VGAT. The resulting pEGFP-N1-VGAT sequence was verified by DNA sequencing reactions. Immunocytochemistry experiments using antibodies against VGAT and GFP showed that the GFP-VGAT fusion protein has the same cellular localization as VGAT endogenous protein in cultured hippocampal neurons (data not shown). The truncated GFPVGAT plasmids were generated by site-directed mutagenesis.

The plasmid encoding the fusion protein of mouse $\mathrm{N}$-terminus of VGAT with glutathione S-transferase (GST) was kindly provided by Bruno Gasnier (Université Paris Descartes, Paris, France) (Dumoulin et al., 1999). Briefly, the first 127 aa of the mouse VGAT were cloned with BamHI and EcoRI into the pGEX4T1 vector (Pharmacia), with minor modifications. The resulting plasmid, pGEX4T1-VIAATNter, was verified by automated sequencing (STAB VIDA). The N-terminus of VGAT from rat and mouse differ in only one base. The high homology between the mouse and rat VGAT in the N-terminal region is in agreement with the results showing the cleavage of the transporter in cultured neurons from both species under excitotoxic conditions (data not shown).

\section{Expression of recombinant GST-VGAT N-terminus}

Expression of the GST-VGAT N-terminus fusion protein (pGEX4T1VGAT N-terminus) and GST (pGEX4T1) was induced by treating an Escherichia coli BL21 culture in the exponential phase of growth $\left(A_{600 \mathrm{~nm}}=\right.$ $0.8-2$ ) with $0.5 \mathrm{~mm}$ isopropyl $\beta$-D-thiogalactoside (BIORON) for $30 \mathrm{~min}$ at $30^{\circ} \mathrm{C}$. The protein, with an apparent molecular mass of $44 \mathrm{kDa}$ in a SDSPAGE gel, was extracted and purified from the bacterial pellet through affinity chromatography on glutathione Sepharose 4B (GE Healthcare), according to manufacturer's recommendations.

\section{Transfection}

Transfected PC-12 cells overexpressing VGAT (pcDNA3.1-VGAT) or the truncated forms of the transporter [pcDNA3.1-VGAT $\Delta(1-52)$ and pcDNA3.1-VGAT $\Delta(1-60)$ ] were generated using a plasmid DNA vector technique. PC-12 cells were transfected using GenePORTER 2 (Gene Therapy Systems). VGAT and truncated cleavage product (tVGAT) overexpression was confirmed by Western blot. The same approach was used to generate PC-12 cell lines overexpressing GFP-VGAT (pEGFPN1-VGAT) and GFP truncated VGAT [pEGFP-N1-VGAT $\Delta(1-52)$ and pEGFP-N1-VGAT $\Delta(1-60)]$.

Transfection of cultured striatal and hippocampal neurons was performed by the calcium phosphate coprecipitation method as described previously, with minor modifications (Jiang et al., 2004; Kaech and Banker, 2006). Briefly, $2 \mu \mathrm{g}$ of plasmid DNA were diluted in Tris-EDTA
(TE) $\mathrm{pH} 7.3$ and mixed with HEPES calcium chloride pH $7.2(2.5 \mathrm{M}$ $\mathrm{CaCl}_{2}, 10 \mathrm{~mm}$ HEPES). This DNA/TE/calcium mix was added to a $2 \times$ HEPES-buffered saline solution ( $270 \mathrm{~mm} \mathrm{NaCl}, 10 \mathrm{~mm} \mathrm{KCl}, 1.4 \mathrm{~mm}$ $\mathrm{Na}_{2} \mathrm{HPO}_{4}, 11 \mathrm{~mm}$ dextrose, $42 \mathrm{~mm}$ HEPES), $\mathrm{pH}$ 7.2. The precipitates were allowed to form for $30 \mathrm{~min}$, with vortex mixing every $5 \mathrm{~min}$, to ensure that the precipitates had similar small sizes. Meanwhile, coverslips with cultured neurons were incubated with cultured conditioned medium with $2 \mathrm{~mm}$ kynurenic acid (Sigma). The precipitate was added drop-wise to each coverslip and incubated at $37^{\circ} \mathrm{C}, 5 \% \mathrm{CO}_{2}$, for $3 \mathrm{~h}$. The cells were then washed with acidic $10 \% \mathrm{CO}_{2}$ equilibrated culture medium containing $2 \mathrm{~mm}$ kynurenic acid and returned to the $37^{\circ} \mathrm{C} / 5 \% \mathrm{CO}_{2}$ incubator for $15 \mathrm{~min}$. Finally, the medium was replaced with the initial culture-conditioned medium, and the cells were further incubated in a $37^{\circ} \mathrm{C} / 5 \% \mathrm{CO}_{2}$ incubator for $48 \mathrm{~h}$ to allow protein expression.

\section{In vitro calpain assay}

Incubation of GST-VGAT N-terminus with calpain. GST-VGAT $\mathrm{N}$-terminus fusion protein $(100 \mu \mathrm{g})$ was diluted in $50 \mathrm{~mm}$ Tris- $\mathrm{HCl}, \mathrm{pH}$ 7.4, $100 \mathrm{~mm} \mathrm{KCl}, 2 \mathrm{~mm}$ dithiothreitol, and $2.5 \mathrm{~mm} \mathrm{CaCl}_{2}$ (or $1 \mathrm{~mm}$ EDTA), and incubated with or without $2.5 \mathrm{U} / \mathrm{ml}$ recombinant calpain I (human erythrocytes, Calbiochem), for $15 \mathrm{~min}$ at $37^{\circ} \mathrm{C}$. Incubation was stopped with concentrated denaturating buffer and boiled for $5 \mathrm{~min}$ at $95^{\circ} \mathrm{C}$. The peptides were then separated by SDS-PAGE with tricine gels, to allow separation of low molecular weight proteins (Schägger and von Jagow, 1987). The gel was stained with Commassie colloidal solution (Candiano et al., 2004). The same experimental procedure was done to transfer the proteins to a PVDF membrane (Millipore), and the bands were cut and sent to $\mathrm{N}$-terminal Edman sequencing, at the protein sequencing facility in University of Leeds, United Kingdom.

Incubation of synaptic vesicles with calpain. Cerebrocortical synaptic vesicles were isolated from the rat brain as described previously (Synaptic Systems - protocol for preparation of P2 and LP2 fractions). The vesicles $(5 \mu \mathrm{g})$ were diluted in $50 \mathrm{~mm}$ Tris- $\mathrm{HCl}, \mathrm{pH} 7.4,100 \mathrm{~mm} \mathrm{KCl}, 2 \mathrm{~mm}$ dithiothreitol, and $2.5 \mathrm{mM} \mathrm{CaCl}_{2}$ (or $1 \mathrm{~mm}$ EDTA), and incubated with or without $2.5 \mathrm{U} / \mathrm{ml}$ recombinant calpain I (human erythrocytes, Calbiochem), for different time points at $37^{\circ} \mathrm{C}$. Where indicated, the experiments were conducted in media with free calcium concentrations of 100 $\mathrm{nM}, 500 \mathrm{nM}$, or $1 \mu \mathrm{M}$, prepared with $0.5 \mathrm{~mm}$ EGTA and the $\mathrm{CaCl}_{2}$ concentrations determined using Maxchelator (http://www.stanford. edu/ cpatton/webmaxc/webmaxclite115.htm) (Patton et al., 2004; McGuigan et al., 2007). Incubation was stopped with concentrated denaturating buffer and no boiling step was done to prevent VGAT aggregation. VGAT cleavage was analyzed by Western blot.

\section{In vitro phosphatase assay}

In vitro phosphatase assay was done as described previously (Bedet et al., 2000). Total cell extracts $(50 \mu \mathrm{g})$ from cultured hippocampal neurons solubilized in RIPA were diluted in the intestinal calf alkaline phosphatase (CIP) buffer, containing $50 \mathrm{~mm}$ Tris- $\mathrm{HCl}, \mathrm{pH}$ 7.9, $10 \mathrm{~mm} \mathrm{MgCl}_{2}, 100$ $\mathrm{mm} \mathrm{NaCl}, 1 \mathrm{~mm}$ dithiothreitol, and supplemented with $0.1 \mathrm{~mm}$ PMSF, 1 $\mu \mathrm{g} / \mathrm{ml}$ chymostatin, $1 \mu \mathrm{g} / \mathrm{ml}$ leupeptin, $1 \mu \mathrm{g} / \mathrm{ml}$ antipain, $1 \mu \mathrm{g} / \mathrm{ml}$ pepstatin (Sigma), and $2 \mathrm{U} / \mathrm{ml} \mathrm{CIP} \mathrm{(New} \mathrm{England} \mathrm{Biolabs).} \mathrm{Incubations} \mathrm{were}$ performed for $1 \mathrm{~h}$ at $37^{\circ} \mathrm{C}$ and stopped with $2 \times$ concentrated denaturating buffer. VGAT protein levels were determined by Western blot.

\section{Intrahippocampal injection of kainate}

Injection. Intrahippocampal injection of kainate (Tocris Bioscience) was performed as described previously (Tomioka et al., 2002; Takano et al., 2005), with minor modifications. Briefly, wild-type adult male mice (C56BL6) and transgenic mice overexpressing human calpastatin (Higuchi et al., 2005) were deeply anesthetized with avertin (2,2,2 tribromoethanol, 2-methyl-2butanol), placed in a stereotaxic apparatus (Stoelting), and given a unilateral injection of $0.1 \mathrm{nmol}$ of kainate (in $0.3 \mu \mathrm{l}$ of PBS) into the hippocampal CA1 region, using a $10 \mu \mathrm{l}$ motorized syringe (Hamilton) after drilling a small hole with a chirurgical drill. The coordinates of the injection were anteriorposterior $-2.3 \mathrm{~mm}$, medial-lateral $-1.5 \mathrm{~mm}$, and dorsal-ventral $-1.7 \mathrm{~mm}$ from the bregma. Two minutes after the needle insertion, kainate was injected at a constant flow rate of $0.05 \mu \mathrm{l} / \mathrm{min}$. The needle remained in place for an additional 2 min to prevent reflux of fluid. The body temperature of mice was monitored and maintained at $37^{\circ} \mathrm{C}$ during surgery and $30 \mathrm{~min}$ after the 
A Cultured hippocampal neurons

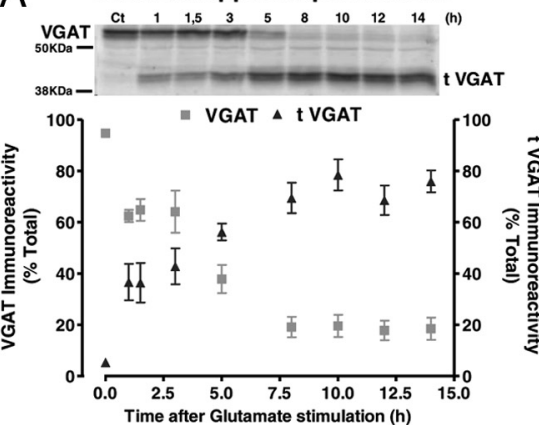

C

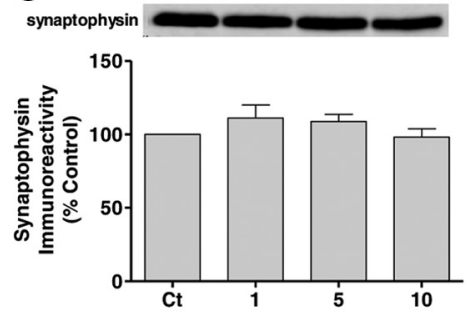

Time after Glutamate stimulation (h)
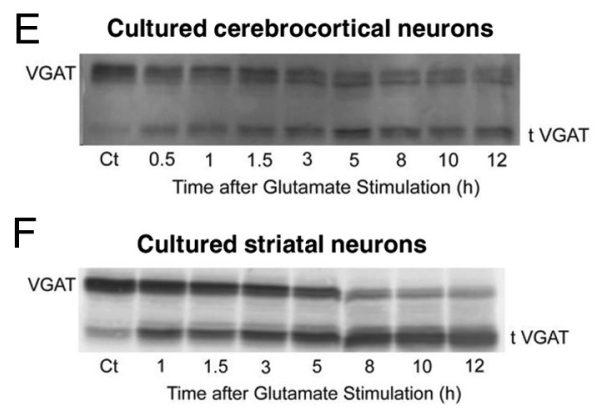

Figure 1. VGAT is cleaved under in vitro and in vivo excitotoxic conditions giving rise to tVGAT. $A$, Cultured hippocampal neurons were subjected to excitotoxic stimulation with glutamate (125 $\mu \mathrm{m}$ glutamate, $20 \mathrm{~min}$ ) and further incubated in cultureconditioned medium. VGAT $(\boldsymbol{A})$ and synaptophysin ( $\boldsymbol{C}$ protein levels were determined by Western blot at the indicated time points after excitotoxic stimulation. The results are the average \pm SEM of six and four independent experiments, respectively, performed in different preparations. Statistical analysis was performed using one-way ANOVA followed by Dunnett's comparison test performed for each condition as compared with the control. $\boldsymbol{B}$, Extracts from control and glutamate stimulated hippocampal neurons were analyzed by Western blot using an antibody absorbed with the peptide used for immunization. The dose-dependent effect of glutamate on the cleavage of VGAT is shown in $\boldsymbol{D}$. Cultured hippocampal neurons were stimulated with 25-100 $\mu \mathrm{m}$ glutamate for $20 \mathrm{~min}$ and further incubated in culture-conditioned medium for $1.5 \mathrm{~h}$. The results are representative of three experiments. $\boldsymbol{E}$ and $\boldsymbol{F}$ show the results obtained in similar experiments using cultured cerebrocortical and striatal neurons, respectively. $\boldsymbol{G}$ shows the effect of in vivo excitotoxicity on the cleavage of VGAT. Adult Wistar rats were injected with kainate $(30 \mathrm{mg} / \mathrm{kg}$, i.p.) and $24 \mathrm{~h}$ later the hippocampi and striatum were collected. Extracts from both brain regions were analyzed by Western blot. The amount of truncated VGAT and synaptophysin in the hippocampus of control and kainate-injected animals was compared using the one-way ANOVA followed by Newman-Keuls multiple comparison test, for three independent experiments. ${ }^{* *} p<0.001$, compared with the control.

injection with a homeothermic heating blanket (Harvard Apparatus), with feedback regulation. The death rate in this experiment was $<5 \%$. Experiments were conducted according to the European Union Directive 86/609/ $\mathrm{EEC}$ on the protection of animals used for experimental and other scientific purposes.

Western blot. Twenty-four hours after injection mice were killed and a $2 \mathrm{~mm}$ section around the hippocampus was taken with the help of a $1 \mathrm{~mm}$ coronal mouse matrix (Harvard Apparatus). The slices were immediately frozen with dry ice and the damaged ipsilateral and contralateral areas of the hippocampal slices were taken using a Harris Unicore $2 \mathrm{~mm}$ tip (Pelco International). Samples were then homogenized and processed for Western blot.

Histochemistry. This was performed as described previously (Takano et al., 2005) with minor modifications. Twenty-four hours after injection of kainate or PBS, mice were deeply anesthetized and perfused through the heart with ice-cold PBS followed be $4 \%$ paraformaldehyde in $0.1 \mathrm{M}$ phosphate buffer, $\mathrm{pH}$ 7.4. The brains were removed, postfixed in the same fixative overnight at $4^{\circ} \mathrm{C}$, and then left in $25 \%$ sucrose in PBS at $4^{\circ} \mathrm{C}$, until sinking in the solution. Coronal sections $(30 \mu \mathrm{m})$ were cut on a freezing microtome (Leica Cryostat CM 3050) and mounted on gelatin-chromium covered glass slides. Sections were then stained with cresyl violet (Sigma) and examined under a Zeiss Axiovert 200 microscope.

\section{Intraperitoneal injection of kainate}

Intraperitoneal injection of kainate was performed as described previously (Wang et al., 2005). Adult rat (Wistar) with an average age of 6 months were injected with a sterile saline solution (0.32 m sucrose, 10 mm HEPES, pH 7.4) containing $10 \mathrm{mg} / \mathrm{kg}$ kainate (Tocris Bioscience). After injection they were left with food and water ad libitum. All the animals used in the present study achieved status epilepticus in the next few hours after injection (Silva et al., 2005). Twenty-four hours after kainate injection the rats were killed and the cerebral cortex and striatum were collected for Western blot analysis. The death rate in this experiment was $<10 \%$. All experiments were done in accordance with the European ethical guidelines for the care and use of laboratory animals (86/609/EEC).

\section{Middle cerebral artery occlusion}

Focal cerebral ischemia was induced by the transient occlusion of the right middle cerebral artery (MCA), using the intraluminal filament placement technique as described previously (Nygren and Wieloch, 2005). Briefly, adult male mice were anesthetized by inhalation of $2.5 \%$ isoflurane (IsobaVet, Schering-Plough Animal Health) in $\mathrm{O}_{2}: \mathrm{N}_{2} \mathrm{O}(30: 70)$. Anesthesia was subsequently reduced to $1.5-1.8 \%$ isoflurane and sustained throughout the occlusion period. Body temperature was kept at $\sim 37^{\circ} \mathrm{C}$ throughout the surgery period. To monitor regional cerebral blood flow (rCBF), an optical fiber probe (Probe 318-I, Perimed) was fixed to the skull at $2 \mathrm{~mm}$ posterior and $4 \mathrm{~mm}$ lateral to bregma and connected to a laser Doppler flow meter (Periflux System 5000, Perimed). A filament composed of 6-0 polydioxanone suture (PSD II, Ethicon) with a silicone tip (diameter of 225-275 $\mu \mathrm{m}$ ) was inserted into the external carotid artery and advanced into the common carotid artery. The filament was retracted, moved into the internal carotid artery, and advanced until the origin of the MCA, given by the sudden drop in $\operatorname{rCBF}$ ( $\sim 70 \%$ of baseline). After 45 $\mathrm{min}$, the filament was withdrawn and reperfusion observed. The animals were placed in a heating box at $37^{\circ} \mathrm{C}$ for the first $2 \mathrm{~h}$ after surgery and thereafter transferred into a heating box at $35^{\circ} \mathrm{C}$, to avoid postsurgical hypothermia. Thirty minutes after the onset of reperfusion, $0.5 \mathrm{ml}$ of $5 \%$ glucose was administered subcutaneously. Temperature and sensorimotor deficits were accessed at 1 and $2 \mathrm{~h}$, and in the morning after the surgery.

The Ethics Committee for Animal Research at Lund University approved animal housing conditions, handling, and surgical procedures. Nine to 11 weeks old C57BL/6J male mice (weight: 21.5 g to 27.9 g; Taconic) were housed under diurnal conditions with ad libitum access to water and food before and after surgery. 
Mice were killed 6 and $24 \mathrm{~h}$ after MCA occlusion (MCAO), and $1 \mathrm{~mm}$ sections were done with the help of a $1 \mathrm{~mm}$ coronal mouse matrix. The slices were immediately frozen with dry ice and the damaged ipsilateral and contralateral areas of the slices were taken using a Harris Unicore $2 \mathrm{~mm}$ tip (Pelco International). Samples were then homogenized and processed for Western blot as described above.

\section{2,3,5-Triphenyltetrazolium}

chloride staining

After $24 \mathrm{~h}$ of recovery, animals were killed to evaluate the infarct volume. The brain was removed and the forebrain was sliced into 1-mm-thick sections using a mouse brain slicer, on ice. The sections were rinsed once in ice-cold $0.9 \%$ sodium chloride $(\mathrm{NaCl})$ for 10 min and subsequently immersed in $50 \mathrm{ml}$ of $0.01 \% \quad 2,3,5$-triphenyltetrazolium chloride (TTC) in $0.9 \% \mathrm{NaCl}$ at $37^{\circ} \mathrm{C}$ for $15 \mathrm{~min}$. Slices were fixed in $4 \%$ formalin and images were acquired with a MicroPublisher 3.3 RTV chargecoupled device camera (QImaging) using standard conditions.

\section{Chemical long-term potentiation}

Cultured hippocampal neurons were exposed to conditions designed to induce chemical long-term potentiation (LTP), as described previously (Shepherd et al., 2006). Briefly, cultured hippocampal neurons with 15 DIV were incubated at $37^{\circ} \mathrm{C}$ and $5 \% \mathrm{CO}_{2}$ for $15 \mathrm{~min}$ in artificial CSF (ACSF) containing $126 \mathrm{~mm} \mathrm{NaCl}$, $5.5 \mathrm{~mm} \mathrm{KCl}, 0.4 \mathrm{~mm} \mathrm{MgSO}_{4}, 1 \mathrm{~mm} \mathrm{NaH}{ }_{2} \mathrm{PO}_{4}$, $25 \mathrm{~mm} \mathrm{NaHCO}_{3}$, and $2 \mathrm{~mm} \mathrm{CaCl}_{2}$, and supplemented with $14 \mathrm{~mm}$ dextrose, $0.2 \mathrm{~mm}$ glycine, and $0.01 \mathrm{~mm}$ bicuculline. After stimulation, the cultures were further incubated in cultureconditioned medium for the indicated time periods.

\section{Statistical analysis}

The immunoreactivity obtained in each experimental condition was calculated as a percentage of the control. Data are presented as mean \pm SEM of at least three different experiments, performed in independent preparations. Statistical analysis of the results was performed using one-way ANOVA analysis followed by either the Dunnett's or Bonferroni post-tests.

\section{Results}

VGAT is cleaved under excitotoxic conditions giving rise to a truncated cleavage product

To understand how excitotoxic conditions influence the protein levels of the vesicular GABA transporter, cultured neurons isolated from different brain regions were stimulated with glutamate (125 $\mu \mathrm{M}$, for $20 \mathrm{~min}$ ) and further incubated in culture-conditioned medium for different periods of time. Stimulation of cultured hippocampal neurons under these conditions induces $40-50 \%$ cell death (Almeida et al., 2005), and Western blot experiments, using an antibody against the $\mathrm{N}$-terminal region of VGAT, showed a biphasic cleavage of the transporter, giving rise to a product of $\sim 46 \mathrm{kDa}$ (tVGAT) (Fig. 1A). VGAT protein levels dropped rapidly by $\sim 40 \%$ within the first hour after the toxic insult, and a secondary decrease in full-length VGAT protein levels, with the same magnitude, was

\section{A $24 \mathrm{~h}$ after lesion}

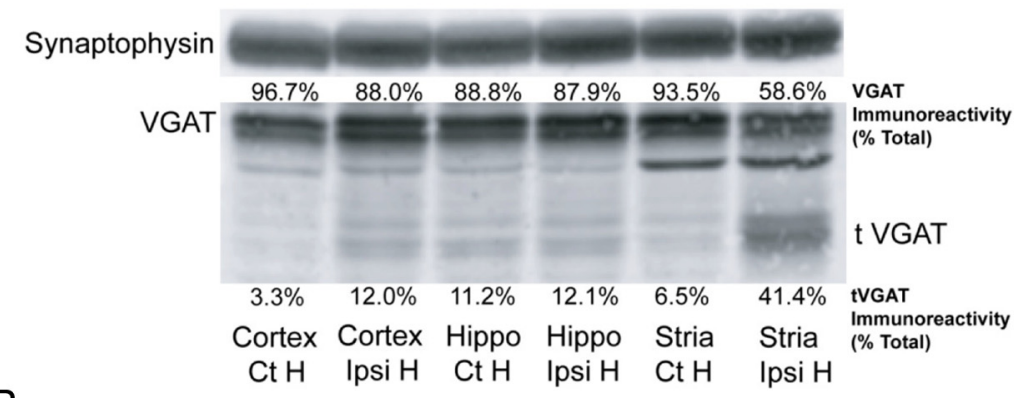

$6 \mathrm{~h}$ after lesion
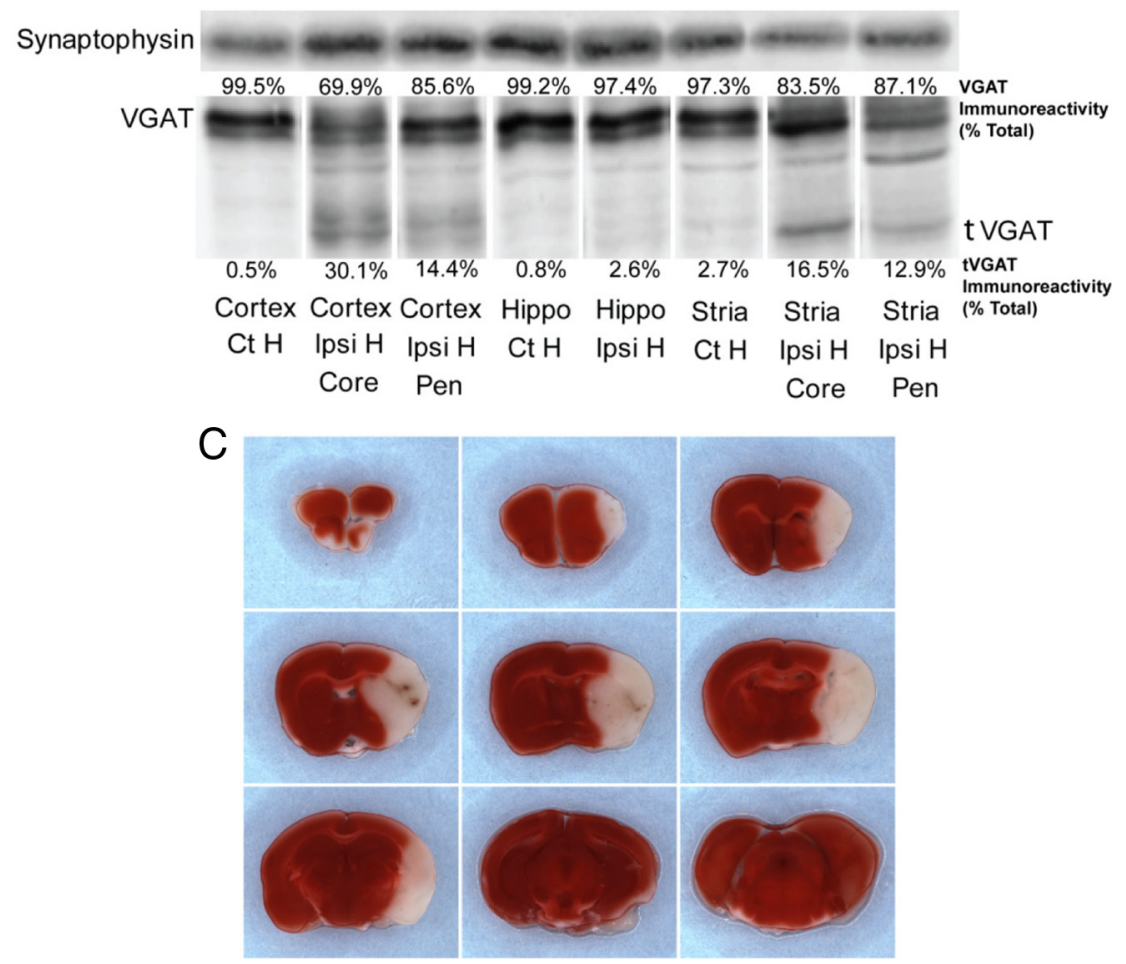

Figure 2. Transient focal ischemia induces VGAT cleavage and tVGAT formation. The changes in VGAT immunoreactivity in the ipsilateral (Ipsi H) and contralateral ( $\mathrm{Ct} \mathrm{H}$ ) brain hemispheres of adult mice $(\mathrm{C} 57 \mathrm{BL} / 6 \mathrm{~J})$ subjected to a transient 45 min occlusion of (Stria) were determined by Western blot, $6 \mathrm{~h}(\boldsymbol{B})$ or $24 \mathrm{~h}(\boldsymbol{A})$ after the lesion. Core and penumbra (pen) regions were dissected in the cerebral cortex and striatum. VVGT and VGAT immunoreactivity is also quantified in $\boldsymbol{A}$ and $\boldsymbol{B}$, respectively. shows the TTC staining of 1-mm-thick sections of the mouse brain, $24 \mathrm{~h}$ after the occlusion, providing an evaluation of the infarct volume and damaged areas in the brain after the $45 \mathrm{~min}$ occlusion of the right middle cerebral artery.

observed at 3-8 h after excitotoxic stimulation. The downregulation of the full-length VGAT was associated with an upregulation of a 46 $\mathrm{kDa}$ immunoreactive band, suggesting that this is a cleavage product of the transporter. The full-length and the cleaved transporter were not detected in Western blot experiments with an antibody that had been previously blocked with the peptide used in the immunization (Fig. 1B).

The effects of glutamate stimulation on VGAT cleavage were also tested using different concentrations of the ligand, and the abundance of full-length and cleaved transporter was evaluated $1.5 \mathrm{~h}$ after stimulation (Fig. $1 \mathrm{D}$ ). The results show a cleavage of the transporter even when neurons were stimulated with glutamate at $50 \mu \mathrm{M}$, a concentration that does not induce neuronal death (data not shown). Under the excitotoxic conditions that caused VGAT cleavage, the synaptic vesicle protein synaptophysin was not affected (Fig. 1C), showing that the cleavage of VGAT 
is not part of a general cascade of protein cleavage. Similar results were obtained in cultured cerebrocortical (Fig. $1 E$ ) and striatal (Fig. $1 F$ ) neurons, using the same protocol for excitotoxic stimulation.

To determine whether VGAT cleavage also occurs under excitotoxic conditions in vivo, VGAT and tVGAT protein levels were analyzed in the hippocampus and striatum of Wistar rats injected with kainate $(30 \mathrm{mg} / \mathrm{kg}$, i.p.), an animal model of temporal lobe epilepsy (Goodman, 1998). Systemic injection of kainic acid reproducibly causes cell death in several brain areas in a seizure-dependent process, the hippocampus being the most affected region (Araújo et al., 2008). Twenty-four hours after kainate injection the truncated transporter was found in the hippocampus and striatum, while synaptophysin protein levels were not changed (Fig. 1G).

The formation of VGAT truncation products was also assessed using the MCAO model of transient focal ischemia (Traystman, 2003). Adult mice (C57BL/6J) were subjected to a transient 45 min occlusion of the left middle cerebral artery, and extracts were prepared from the ipsilateral (Ipsi H) and contralateral $(\mathrm{Ct} \mathrm{H})$ brain hemispheres (cortex, striatum, and hippocampus) 6 and $24 \mathrm{~h}$ after injury. A downregulation of VGAT protein levels associated with an upregulation of tVGAT was observed in the ipsilateral striatum and cerebral cortex $6 \mathrm{~h}$ after the ischemic insult (Fig. $2 B$ ). This effect was more significant in the core than in the penumbra region, and a significant amount of tVGAT was still present in the damaged (ipsilateral) striatum $24 \mathrm{~h}$ after MCAO (Fig. $2 \mathrm{~A}$ ). In contrast, MCAO did not induce cleavage of VGAT in the hippocampus, a brain region that is not affected in this model of ischemia, as observed in 1-mm-thick sections of the mouse brain, $24 \mathrm{~h}$ after the occlusion, using TTC staining (Fig. 2C).

\section{VGAT is cleaved under conditions designed to induce chemical LTP}

Since low concentrations of glutamate also lead to the cleavage of VGAT (Fig. 1D), we investigated the effects of increased synaptic activity induced by stimulation of the cells with $0.2 \mathrm{~mm}$ glycine and $0.01 \mathrm{~mm}$ bicuculline for $15 \mathrm{~min}$. This protocol stimulates excitatory synaptic activity and was previously shown to induce chemical LTP (Shepherd et al., 2006). The cells were further incubated in culture-conditioned medium for the indicated periods of time before preparation of extracts. Small but significant amounts of tVGAT were observed 5-8 h after stimulation, when chemical LTP is typically observed (Shepherd et al., 2006), and this effect was also sensitive to the calpain inhibitor ALLN (Fig. 3).

\section{tVGAT has a long half-life}

The results of Figure $1 \mathrm{~A}$ show that excitotoxic stimulation of hippocampal neurons with glutamate causes a time-dependent cleavage of VGAT, giving rise to a truncated product. Interestingly, calculation of the total protein (full-length + truncated VGAT immunoreactivity) expressed in the cells after the insult showed no significant differences for the different incubation periods tested, up to $12 \mathrm{~h}$ (Fig. $4 \mathrm{~A}$ ). tVGAT is present even $24 \mathrm{~h}$ after the glutamate stimulation (Fig. $4 B$ ). These results strongly suggest that truncated VGAT has a high stability in the cell.

The replenishment of the pool of full-length transporters after cleavage depends on the turn-over rate, which can be assessed by blocking translation activity. Incubation of hippocampal neurons with the translation inhibitor anisomycin (Calbiochem; 5 $\mu \mathrm{M}$ ) for $8 \mathrm{~h}$ did not change significantly total VGAT protein levels

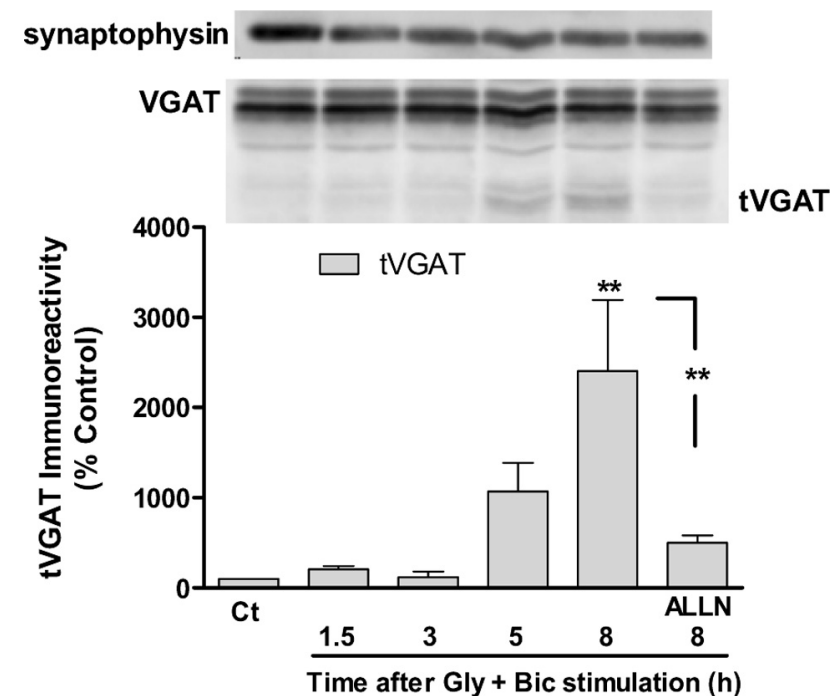

Figure 3. VGAT is cleaved under conditions that induce chemical LTP. Cultured hippocampal neurons (15 DIV) were stimulated with $0.2 \mathrm{~mm}$ glycine and $0.01 \mathrm{~mm}$ bicuculline for $15 \mathrm{~min}$ in ACSF. The cells were then incubated in culture-conditioned medium for the indicated periods of time before preparation of the extracts. Where indicated, the cells were pre-incubated with the calpain inhibitor ALLN $(50 \mu \mathrm{m})$ for $2 \mathrm{~h}$, and the inhibitor was also present in the cultureconditioned medium after excitotoxic stimulation. The results were analyzed by Western blot, using an antibody against VGAT. The results are the average \pm SEM of three different experiments performed in independent preparations. Statistical analysis was performed using the one-way ANOVA followed by Newman-Keuls multiple comparison test. ${ }^{* *} p<0.01$, compared with the control or with cells exposed to chemical LTP in the absence of ALLN.

in control conditions (Fig. 4C), showing that the protein has a rather slow turn-over rate. In contrast, inhibition of translation for the same period of time decreased significantly the protein levels of GluN1, a subunit of the NMDA receptors (Fig. 4D). The mRNA for VGAT was also downregulated to some extent under excitotoxic conditions (Fig. $4 E$ ). This is likely due to active degradation of VGAT transcripts since inhibition of transcription with actinomycin D (Calbiochem), for the same period of time, did not change significantly VGAT mRNA (Fig. $4 E$ ). Together, the results showing a low turn-over rate of VGAT and the high stability of tVGAT indicate that in surviving neurons the truncated protein replaces the full-length transporter for $12-24 \mathrm{~h}$ after excitotoxic stimulation.

\section{Calpain cleaves VGAT giving rise to tVGAT, under in vitro and in vivo excitotoxic conditions}

Chemical inhibitors of different classes of proteases (calpains, caspases, cathepsins, and the proteasome) were used to dissect their relative role in VGAT cleavage under excitotoxic conditions. Both calpain inhibitors used, ALLN and MDL28170 (Calbiochem), prevented VGAT cleavage and tVGAT formation mainly in the earlier phase, observed $1.5 \mathrm{~h}$ after glutamate stimulation (Fig. 5A). The second and slower phase of VGAT cleavage, observed 2-7 h after glutamate stimulation (see Fig. $1 A$ ), was only partially sensitive to calpain inhibition (Fig. $5 B$ ). In agreement with the role of calpains in VGAT cleavage, ALLN also prevented the cleavage of the transporter in hippocampal neurons incubated under conditions that induce chemical LTP (Fig. 3).

Since VGAT cleavage was not fully inhibited by calpain inhibitors, we investigated the putative role of caspases and cathepsins in VGAT downregulation. Z-VAD FMK (Biomol), a general inhibitor of caspases, did not affect glutamate- 
induced VGAT cleavage (Fig. 5D), indicating that caspases do not contribute to VGAT cleavage under excitotoxic conditions. Cathepsins, mainly the isoform $\mathrm{B}$ and $\mathrm{L}$, have been described as being involved in protein degradation in ischemic cell death (Yamashima, 2000). The use of specific pharmacological inhibitors of cathepsin B and L (CA-074 Me and Cathepsin L Inhibitor III, respectively, at 50 and $10 \mu \mathrm{M}$, Calbiochem) showed that these proteases do not contribute to the cleavage of VGAT under excitotoxic conditions (Fig. 5E). Furthermore, cathepsin inhibitors did not show a significant effect on VGAT cleavage when tested in the presence of the calpain inhibitor $(50 \mu \mathrm{M})$. The role of the proteasome in glutamate-induced VGAT cleavage was tested using the inhibitor MG132 (Calbiochem; $1 \mu \mathrm{M}$ ). The effect of the proteasome inhibitor was tested $6 \mathrm{~h}$ after excitotoxic stimulation due to its toxicity at longer incubation periods (Rideout and Stefanis, 2002; Butts et al., 2005). MG132 did not affect glutamate-induced VGAT cleavage (Fig. $5 F$ ), ruling out the contribution of the proteasome.

To confirm the effect of calpain on VGAT, we performed in vitro experiments using isolated cerebrocortical synaptic vesicles and recombinant calpain I (Fig. $5 C)$. The results show a time-dependent cleavage of VGAT in the presence of calpain and the formation of a truncated VGAT with an apparent molecular mass of $\sim 46-47 \mathrm{kDa}$, similar to the results obtained in cultured hippocampal neurons (Fig. 1A). As expected, the effects of calpain were $\mathrm{Ca}^{2+}$-dependent as follows: there was no VGAT cleavage in a $\mathrm{Ca}^{2+}$ free medium (containing 1 mM EGTA), but tVGAT formation was observed at physiological free calcium concentrations (100 nM and higher). As expected, VGAT cleavage in a $\mathrm{Ca}^{2+}$-containing medium was sensitive to the calpain inhibitor MDL28170 $(50 \mu \mathrm{M})$. Synaptic vesicle extracts typically showed two bands immunoreactive with the antiVGAT antibody. The most abundant band, corresponding to an apparent molecular mass of $58 \mathrm{kDa}$, is analogous to the transporter identified in cultured neurons.

The second band, with an apparent molecular mass of 50-52 kDa, may correspond to an isoform of the vesicular GABA transporter that has been described previously (Chessler et al., 2002; Ebihara et al., 2003; Oh et al., 2005; Suckow et al., 2006). In the experiments with cultured hippocampal neurons, this putative isoform was only observed with some batches of the polyclonal antibody, and it was less abundant than the $58 \mathrm{kDa}$ band (data not shown).

The role of calpains in VGAT cleavage under excitotoxic conditions was further investigated in vivo, using the intrahippocam-
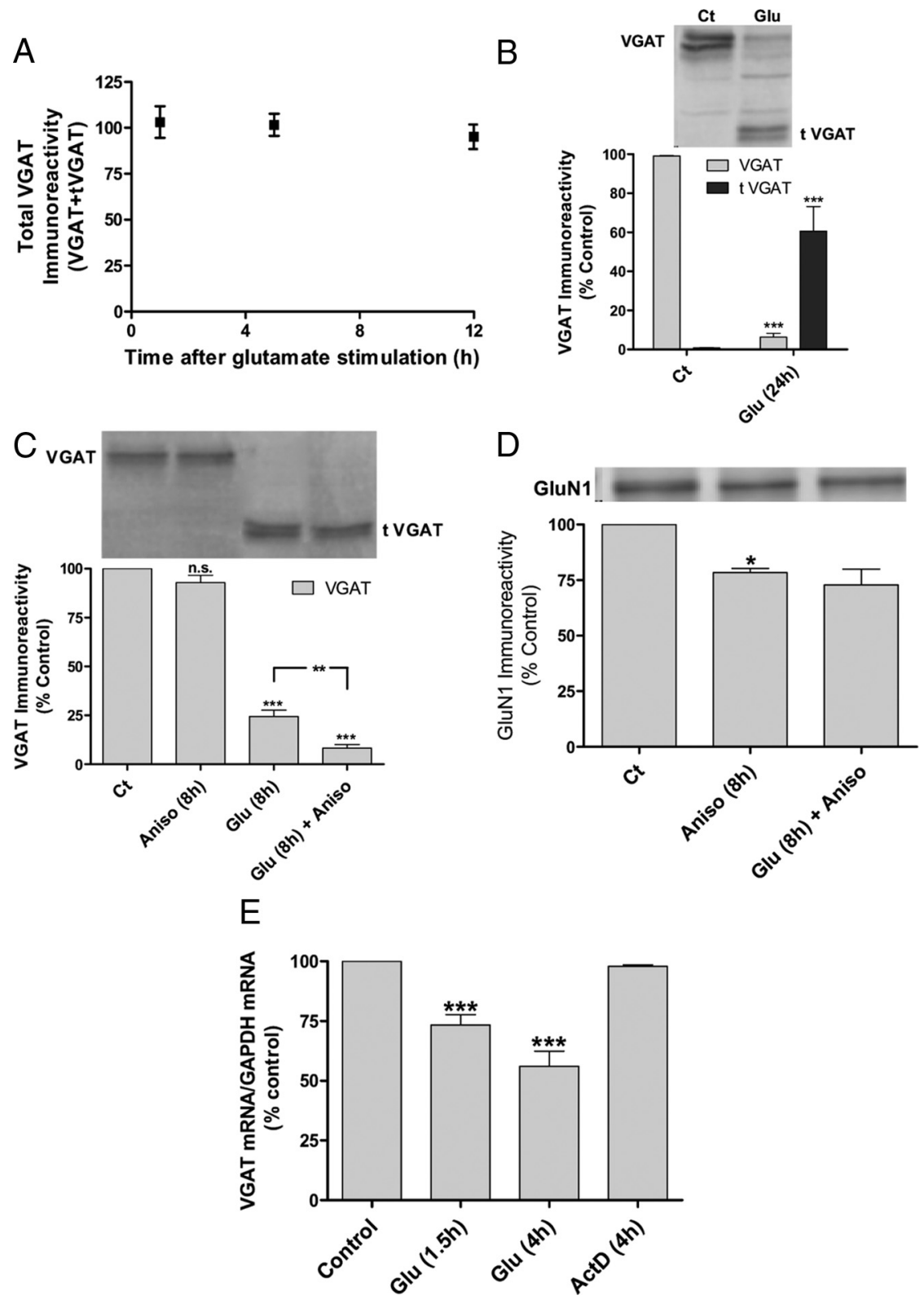

Figure 4. TVGAT has a long half-life. $A-C$, Cultured hippocampal neurons were subjected to excitotoxic stimulation with glutamate (125 $\mu \mathrm{m}$ glutamate, $20 \mathrm{~min}$ ) and further incubated in culture-conditioned medium for the indicated period of time. VGAT and tVGAT protein levels were determined by Western blot. The results are the average \pm SEM of $4(A, B, D, E)$ or $4-12(C)$ independent experiments, performed in different preparations (in $A$ the results were taken from Fig. $1 A$ ). Where indicated the cells were stimulated in the presence or in the absence of the protein synthesis inhibitor anisomycin $(5 \mu \mathrm{M})$, and were further incubated in culture-conditioned medium for $8 \mathrm{~h}$, in the presence or in the absence of the translation inhibitor. $\boldsymbol{E}$, Cultured hippocampal neurons were subjected to excitotoxic stimulation with glutamate (125 $\mu \mathrm{m}$ glutamate, $20 \mathrm{~min}$ ) and further incubated in cultureconditioned medium for the indicated periods of time. Alternatively, cultures were incubated with the transcription inhibitor actinomycin D $(1.5 \mu \mathrm{M})$ for $4 \mathrm{~h}$. Total RNA was extracted and VGAT and Gapdh mRNA were semiquantified through real-time PCR. Statistical analysis was performed using one-way ANOVA followed by Dunnett's $(\boldsymbol{A})$ or Bonferroni's $(\boldsymbol{B}-\boldsymbol{E})$ multiple comparison Statistical analysis was performed using one-way ANOVA followed by Dunnett's $(\boldsymbol{A})$ or Bonferroni's $(\boldsymbol{B}-\boldsymbol{E})$ multiple compa
tests. ${ }^{*} p<0.05,{ }^{* * *} p<0.001$, compared with the control; ${ }^{* *} p<0.01$ for the indicated comparison; n.s., not significant.

pal kainate injection and transgenic mice overexpressing calpastatin (h/CAST), a natural inhibitor of calpains (Higuchi et al., 2005; Takano et al., 2005). The animals were genotyped for the presence of the additional calpastatin human gene introduced in the mice genome, to ensure that all mice used in the experiments were transgenic, overexpressing calpastatin. Kainate injection induced VGAT cleavage in the hippocampus of wild-type mice but not in transgenic $\mathrm{h} / \mathrm{CAST}$ mice, which display low calpain activity (Fig. 6A). As expected, no changes were observed in 
A

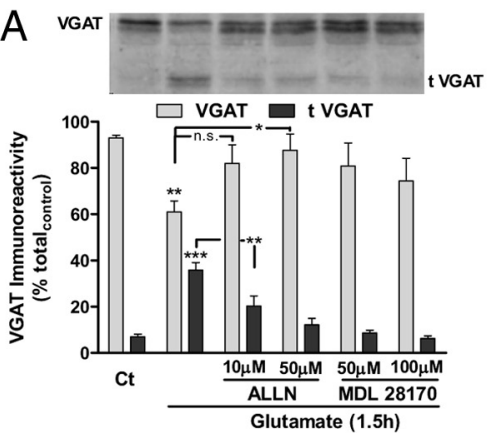

C

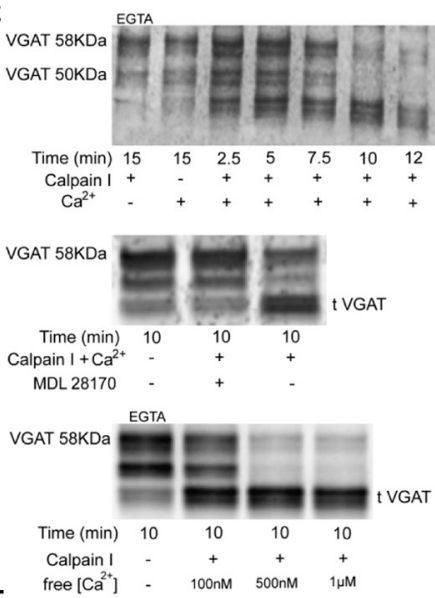

E
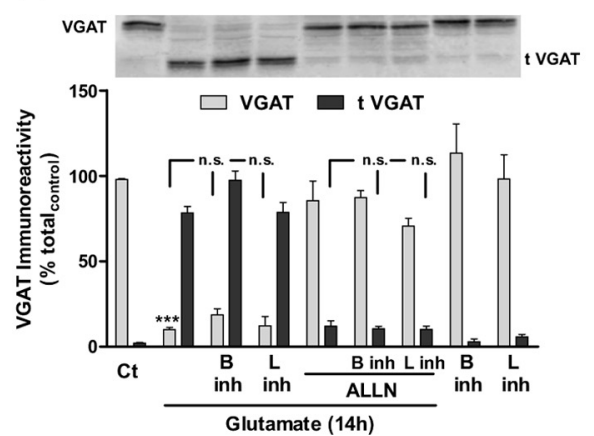

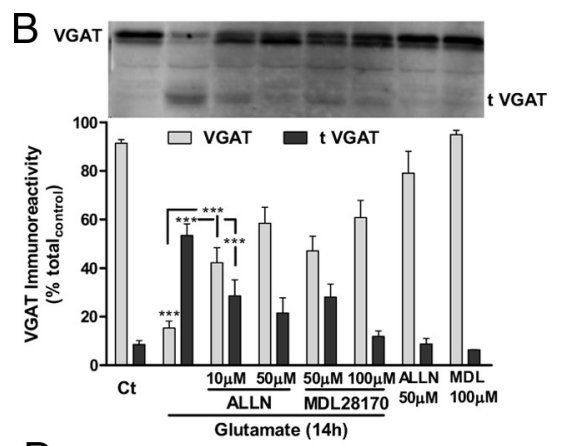

D
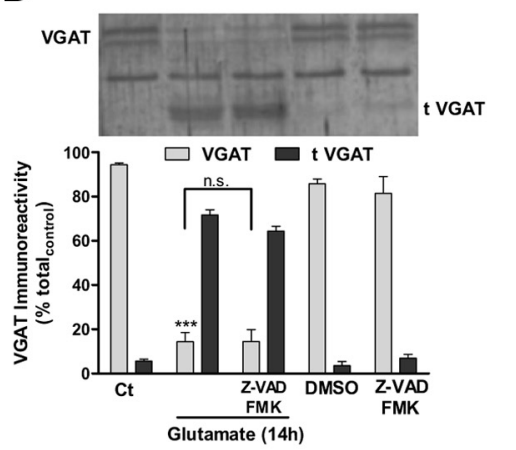

$\mathrm{F}$

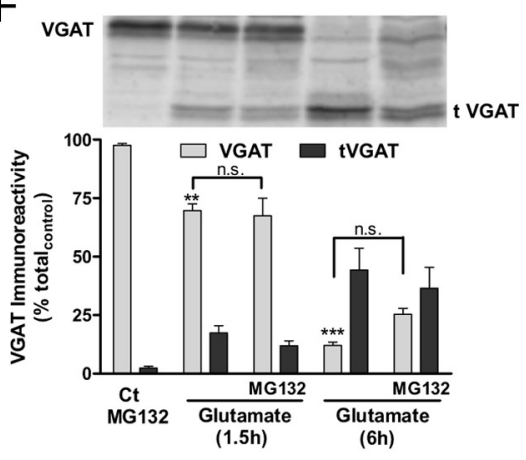

Figure 5. Calpain cleaves VGAT giving rise to tVGAT. $A, B$, Cultured hippocampal neurons were pre-incubated $(2 \mathrm{~h})$ with the calpain inhibitors MDL $28170(50$ and $100 \mu \mathrm{M})$ or ALLN (10 and $50 \mu \mathrm{M})$, before and during glutamate stimulation $(125 \mu \mathrm{M}, 20$ $\mathrm{min})$. The cells were then incubated in culture-conditioned medium for $1.5 \mathrm{~h}(\boldsymbol{A})$ or $14 \mathrm{~h}(\boldsymbol{B})$ with calpain inhibitors. The results are the average \pm SEM of at least five different experiments performed in independent preparations. $C$, Cerebrocortical synaptic vesicles $(5 \mu \mathrm{g})$ were incubated with recombinant calpain I $(2.5 \mathrm{U} / \mathrm{ml})$ for the indicated periods of time at $37^{\circ} \mathrm{C}$, in the presence $(100$ $\mathrm{nm}, 500 \mathrm{~nm}, 1 \mu \mathrm{m}, 2.5 \mathrm{~mm} \mathrm{Ca}^{2+}$ ) or in the absence (1 mM EGTA) of calcium. Where indicated the effect of the calpain inhibitor MDL $28170(50 \mu \mathrm{m})$ was tested. The results are representative of at least three independent experiments. $\boldsymbol{D}$, The effect of the caspase inhibitor Z-VAD-FMK (50 $\mu \mathrm{m}$ ) (and DMSO as vehicle) on glutamate-evoked VGAT cleavage was tested using the experimental conditions described in $\boldsymbol{B}$. The effect of cathepsin B (Ca-074 Me, $50 \mu \mathrm{m}$ ) and L (Inhibitor III, $10 \mu \mathrm{m}$ ) inhibitors is shown in $\boldsymbol{E}$. Cumulative inhibition of calpains ( $A L L N, 50 \mu \mathrm{M}$ ) and cathepsins was also tested in $\boldsymbol{E}$. $\boldsymbol{F}$ shows experiments where the effect of the proteasome inhibitor MG132 $(1 \mu \mathrm{M})$ on VGAT cleavage was tested. In the latter experiments the cells were preincubated for $30 \mathrm{~min}$ with the proteasome inhibitor before the glutamate stimulation. After excitotoxic stimulation, the cells were incubated in cultureconditioned medium in the presence or in the absence of the tested inhibitor, for the indicated periods of time. In all experiments the extracts were analyzed by Western blot with an antibody against VGAT. In the results of $\boldsymbol{D}-\boldsymbol{F}$ the average \pm SEM of at least four experiments was performed in independent preparations. Statistical analysis was performed using one-way ANOVA followed by Bonferroni's multiple comparison test. ${ }^{*} p<0.05,{ }^{* *} p<0.01$, ${ }^{* * *} p<0.001$; n.s., not significant, compared with the control protein levels for VGAT or tVGAT or for the indicated comparisons.

the contralateral hemisphere. Control experiments, consisting in the injection of PBS, the kainate vehicle, into the hippocampus, did not induce VGAT cleavage in WT or transgenic mice. These results show that calpain also plays a role in VGAT cleavage under excitotoxic conditions in vivo. Kainate toxicity under the experimental conditions used was confirmed by staining brain slices with cresyl violet. In contrast with the increase in cell death observed upon injection of kainate in WT mice, no significant effects were observed in transgenic mice overexpressing calpastatin, showing that calpain contributes to neuronal death (Fig. 6B).

VGAT is truncated in two cleavage sites, in the $\mathrm{N}$-terminal region

According to the predicted topology, the VGAT N-terminal region is directed toward the cytoplasm, whereas the C-terminal region is located within the synaptic vesicles (McIntire et al., 1997; Martens et al., 2008). This suggests that the $\mathrm{N}$-terminal region of the transporter may be targeted by calpains under excitotoxic conditions. This hypothesis is further supported by the presence of a putative PEST sequence in the $\mathrm{N}$-terminal region of VGAT (PEST score: +11.17). These amino acid sequences, which are enriched in proline, glutamate, serine, and threonine, are typically targeted by calpains that may then cleave neighbor sequences (Rogers et al., 1986; Rechsteiner and Rogers, 1996) (Fig. $7 A$ ). As a first approach to further investigate the VGAT amino acid sequence(s) targeted by calpains, we performed Western blot experiments using antibodies that bind specifically to different epitopes on VGAT, in the $\mathrm{N}$ - and $\mathrm{C}$-terminal regions of the protein. Truncated VGAT reacted with the antibodies raised against the $\mathrm{C}$ - (amino acids 500-525) and N- (amino acids 75-87) terminal regions of VGAT, but was not detected with an antibody against amino acids $1-20$, suggesting that the cleavage site is within the N-terminal region of VGAT, probably between amino acids $20-75$ (Fig. $7 A, B$ ).

To further evaluate the putative cleavage site(s) in the $\mathrm{N}$-terminal region of VGAT we used the algorithm of Tompa et al. (2004), which allows predicting amino acid sequences targeted by calpain. The results of Figure $7 C$ show that the PEST sequence (amino acids 64-83) is located near the region where the highest scores are found (Fig. 7C). Since it was proposed that calpains cleave their substrates in rather disordered segments of the protein (Tompa et al., 2004), we used bioinformatics tools to predict the disorder tendency along the VGAT amino acid sequence (Ishida and Kinoshita, 2008). The results of Figure $7 D$ show that the protein is more disordered at the $\mathrm{N}$-terminus, particularly in the sequence between amino acids 50-115.

A careful analysis of the results of the Western blot experiments using extracts from cultured hippocampal neurons subjected to excitotoxic conditions and cerebrocortical vesicles incubated with calpain shows two close immunoreactive bands, both for the full-length and the truncated VGAT. The double 
A

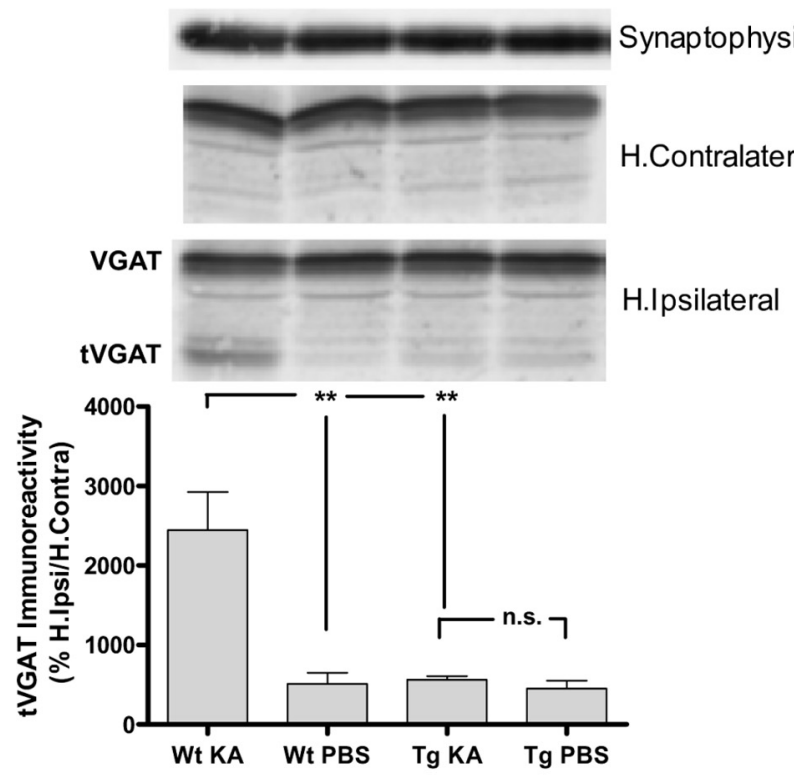

B Wild type / Kainate

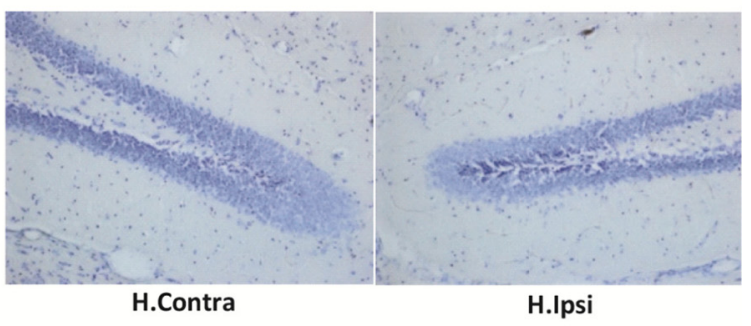

Tg hCAST / Kainate

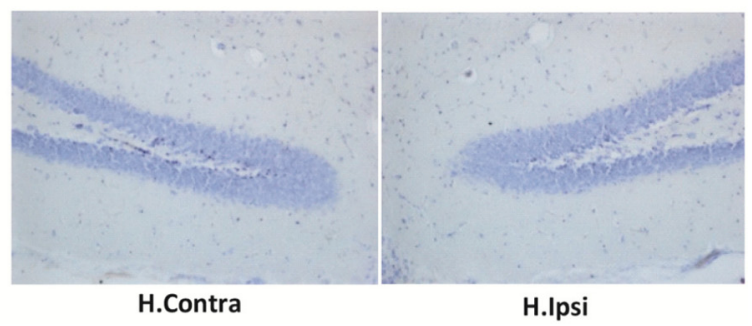

Figure 6. Kainate-induced VGAT cleavage is abrogated in hCAST-Tg mice. $A$, Adult Wt and Tg $\mathrm{h} /$ CAST mice (C56BL6) were injected with kainate $(0.1 \mathrm{nmol}$ in $0.3 \mu$ lof phosphate buffer) in the right hippocampus, and $24 \mathrm{~h}$ later the ipsilateral and the contralateral hippocampi were collected from the coronal sliced brain. Hippocampal extracts were made and analyzed by Western blot against VGAT, human calpastatin, and synaptophysin (as loading control). Statistical analysis was performed using one-way ANOVA followed by Bonferroni's multiple comparison test $\left({ }^{* *} p<0.01\right.$; n.s., not significant). B, Adult Wt and Tg h/CAST mice were injected with kainate as in $\boldsymbol{A}$ and $24 \mathrm{~h}$ later the animals were perfused with phosphate buffer and paraformaldehyde. The brain was collected and sliced $(30 \mu \mathrm{m})$. Slices were stained with cresyl violet. Images show staining of the ipsilateral and contralateral hippocampal dentate gyrus. The results are representative of at least three independent experiments, performed in different animals.

band for full-length VGAT has already been described as a phosphorylated and dephosphorylated forms of VGAT, although it remains to be determined how phosphorylation affects the activity of the transporter (Bedet et al., 2000). Accordingly, in extracts incubated with CIP VGAT was observed as a single band. However, CIP showed no effect on the mobility of two close bands corresponding to truncated VGAT, suggesting that excitotoxic stimulation gives rise to two different cleavage products (Fig. 7E).
The calpain cleavage sites were determined by incubating recombinant calpain with a GST-fusion protein with the N-terminal region of VGAT. The cleavage products were separated by SDS-PAGE, transferred to a PVDF membrane, and sequenced by N-terminal Edman sequencing. Three cleavage sites were observed, at amino acids 7, 52, and 60 (Fig. 7F). However, only two of these sites (amino acids 52 and 60) matched the results obtained in neuronal cultures. The GST protein alone was not affected by calpain (Fig. $7 F$ ). To confirm the VGAT cleavage site(s) following excitotoxic stimulation, $\mathrm{PC} 12$ cells were transfected with a construct corresponding to VGAT truncated at amino acids 52 or 60 in the pcDNA3.1VGAT plasmid vector. Western blot experiments were performed to compare the mobility of the truncated transporter formed upon excitotoxic stimulation of hippocampal neurons and the transporters expressed in transfected PC12 cells. The results show a similar mobility in SDS-PAGE of tVGAT expressed in hippocampal neurons and the truncated VGAT expressed in PC12 cells (Fig. 7G).

\section{VGAT cleavage changes the distribution of the protein along axons}

Since the N-terminal region of VGAT is located outside the synaptic vesicles, it is likely to play a role in the trafficking of the protein along the cell body and neurites, through interaction with other cytoplasmic proteins. To further investigate how VGAT cleavage affects the subcellular distribution of the protein, we compared the distribution of GFP fusion proteins with VGAT or tVGAT. We used the plasmid vector pEGFP-N1 that fuses GFP to the C-terminus of VGAT, and the truncated form of GFP-VGAT was produced by in situ mutagenesis. Control imunocytochemistry experiments showed that the distribution of GFP-VGAT colocalized with endogenous VGAT along neurites in cultured hippocampal neurons (data not shown), showing that the fusion of GFP with the C-terminus of VGAT did not alter its intracellular traffic.

The cellular distribution of GFP-VGAT and GFP-tVGAT (1-52 and 1-60) was compared in cultured striatal neurons instead of cultured hippocampal neurons because the former preparation is enriched in GABAergic neurons. The cells were cultured for $11 \mathrm{~d}$ to allow synaptic differentiation, and the distribution of the GFP fusion proteins was analyzed by confocal microscopy in GABAergic neurons, identified by immunocytochemistry with an antibody against GABA. GFP-VGAT showed a punctate distribution along neurites, which colocalized with synaptophysin, a common synaptic marker (Fig. $8 A$ ). In contrast, the GFP-tVGAT forms [GFP-VGAT $\Delta(1-52)$ (Fig. $8 B$ ) and GFP-VGATA(1-60) (Fig. 8C)] were distributed homogeneously along neurites with no colocalization with synaptophysin. Control Western blot experiments showed that the fusion proteins expressed in $\mathrm{PC} 12$ cells had the expected apparent molecular weight and were recognized by both VGAT and GFP antibodies (Fig. $8 D$ ).

The distribution of endogenous VGAT was also compared in cultured hippocampal neurons under control conditions and after excitotoxic stimulation with glutamate (125 $\mu \mathrm{M}, 20 \mathrm{~min})$. Immunocytochemistry experiments with an antibody against the $\mathrm{N}$-terminal region of VGAT (amino acids 75-87) show a significant reduction in the punctated distribution of VGAT along neurites 1.5 and $8 \mathrm{~h}$ after the toxic insult (Fig. $8 E$ ). At the latter time point $>80 \%$ of VGAT was in the truncated form (see Fig. $1 A$ ), showing a homogeneous distribution along neurites. This pattern of VGAT distribution resembles the immunoreactivity observed for the transfected truncated proteins (Fig. $8 B, C$ ). Together, the results clearly show that the cleavage of VGAT alters the subcel- 
A

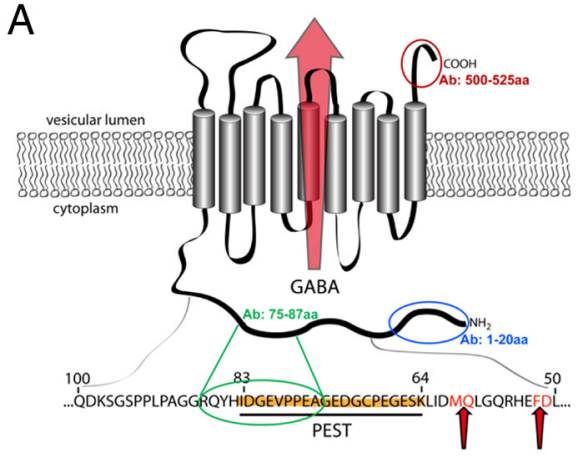

B
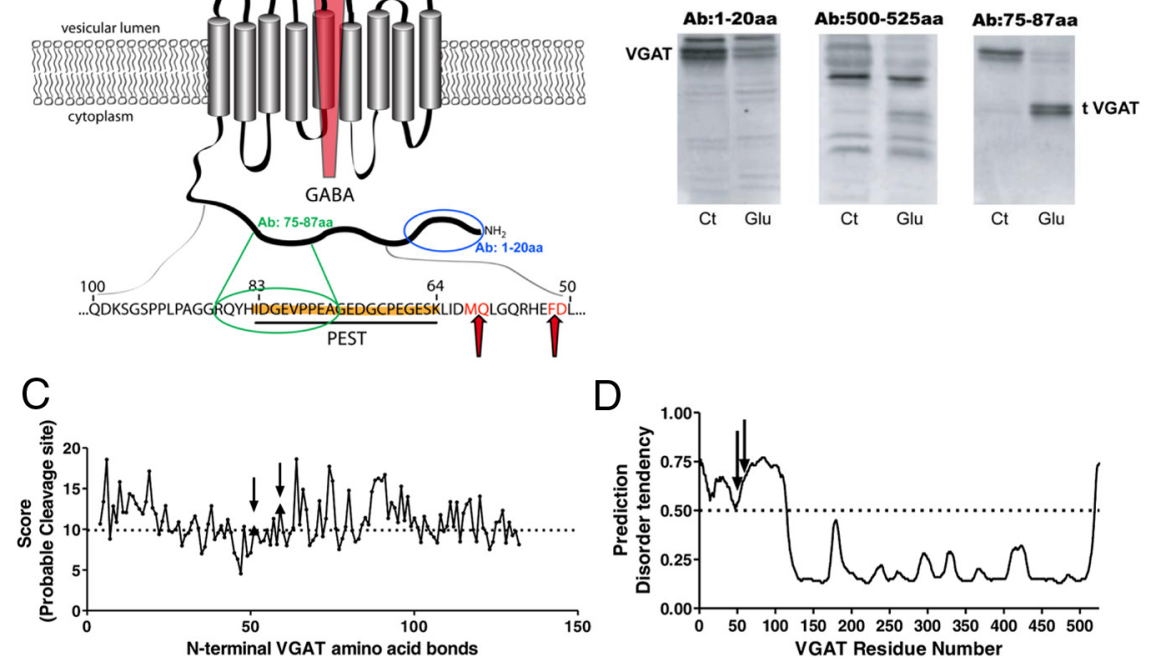

E

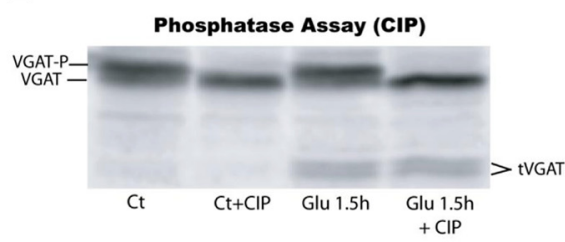

G

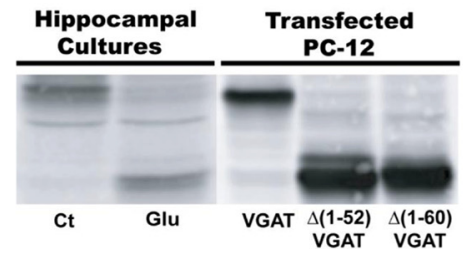

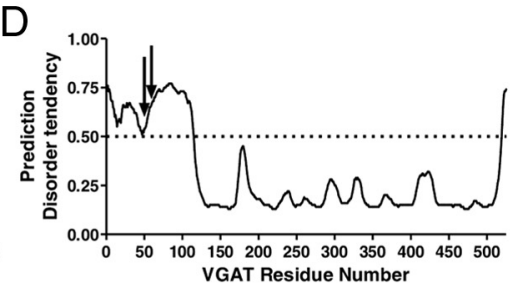

F

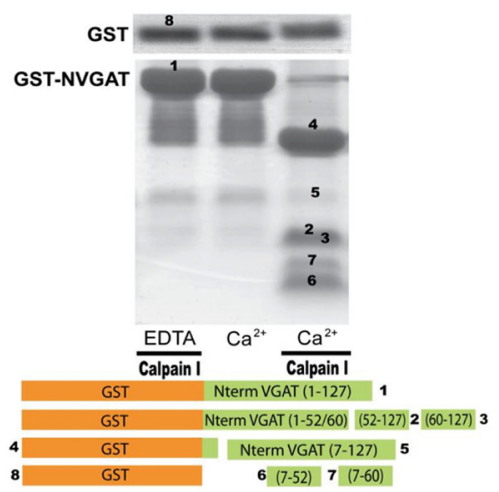

Figure 7. VGAT is truncated in two cleavage sites in the N-terminal region. $A$, Predicted topology of VGAT, showing the antibody (Ab) binding sites and the calpain cleavage sites identified (51-52 and 59-60). The antibody against amino acids $75-87$ recognizes both the full-length and truncated VGAT (Fig. 1A). B, Western blot of extracts prepared from control and glutamate- (125 $\mu \mathrm{M}, 20 \mathrm{~min}$ ) stimulated cultured hippocampal neurons. The extracts were prepared $12 \mathrm{~h}$ after the excitotoxic insult, and the membranes were probed with antibodies against the indicated VGAT amino acid sequences. C, Analysis of the probability of cleavage by calpain in the N-terminal region of VGAT based on the model for prediction of calpain cleavage sites published in the study by Tompa et al. (2004). Arrows point to the predicted calpain cleavage sites identified in the present work. D, Prediction of the disorder tendency of VGAT based on a bioinformatic analysis of the amino acid sequence of the protein (Ishida and Kinoshita, 2008). Arrows point to the predicted calpain cleavage sites identified in the present work. $E$, Extracts from cultured hippocampal neurons subjected to excitotoxic stimulation with glutamate (and further incubated in culture-conditioned medium for $1.5 \mathrm{~h}$ ) were incubated with $\mathrm{CIP}(2 \mathrm{U} / \mu \mathrm{l})$ for $1 \mathrm{~h}$ at $37^{\circ} \mathrm{C}$, in the presence of protease inhibitors. After incubation, the extracts were analyzed by Western blot with an antibody against VGAT. F, The GST-N-terminal VGAT fusion protein and GST protein (100 $\mu \mathrm{g}$ ) were incubated with or without recombinant calpain I $(2.5 \mathrm{U} / \mathrm{ml})$ in the presence of calcium $\left(2.5 \mathrm{~mm} \mathrm{Ca}{ }^{2+}\right)$, for $15 \mathrm{~min}$ at $37^{\circ} \mathrm{C}$. The peptides were separated by SDS-PAGE and were stained immediately (or after transfer to a PVDF membrane) with Commassie blue. The PVDF membrane with the indicated fragments was processed for N-terminal Edman sequencing. G, Comparison of VGAT and tVGAT expressed in cultured hippocampal neurons subjected to excitotoxic stimulation with glutamate and in transfected PC12 cell lines expressing the cDNA of VGAT (pcDNA 3.1-VGAT) and the truncated VGAT forms created by mutagenesis [pcDNA3.1-VGAT $\Delta(1-52)$ and pcDNA3.1-VGAT $\Delta(1-60)]$. Extracts were analyzed by Western blot with an antibody against VGAT.

lular distribution of the protein, and this may affect GABAergic synaptic transmission because tVGAT is no longer at the synapses.

\section{Proposed mechanism of VGAT cleavage and tVGAT formation in the GABAergic synapses}

A few intrinsic signals that control the trafficking of vesicular neurotransmitter transporters have been identified, including the dileucine motif present in multiple transporters, an acidic cluster, present in the vesicular monoamine transporter 2
(VMAT2), and a polyproline motif characterized in the vesicular glutamate transporter 1 (VGLUT) (Fei et al., 2008). However, up to now no such signals have been identified for VGAT. Analysis of the $\mathrm{N}$-terminal region of VGAT shows four putative trafficking signals (Fig. 9A), as follows: two dileucine motifs (A, C), which can be composed of two leucines or one leucine and an isoleucine, one acidic motif (B) and a proline motif (D). When VGAT is truncated by calpain the first two motifs (A, B) are lost, but the others $(\mathrm{C}, \mathrm{D})$ are kept in the truncated proteins and may affect the subcellular distribution of the transporter. To further investigate how VGAT cleavage affects its subcellular distribution, we generated by directed in situ mutagenesis a mutated form of GFP-VGAT lacking amino acids 40-90 [GFP-VGAT $\Delta(40-90)$ ]. This form of VGAT does not contain the PEST sequence and the identified calpain cleavage sites, but is endowed with three of the four putative trafficking signals discussed above. Hippocampal neurons transfected with GFP$\operatorname{VGAT} \Delta(40-90)$ were subjected to excitotoxic stimulation with glutamate ( $125 \mu \mathrm{M}, 20 \mathrm{~min})$, and the amount of mutant transporter present in the cells was determined by Western blot, with an antibody against GFP. The results show that the mutant transporter is resistant to calpain cleavage in hippocampal neurons stimulated under conditions that lead to the cleavage of the full-length transporter (Fig. 9B). Immunocytochemistry experiments were performed to determine the cellular distribution of GFP-VGATA (40-90) in transfected cultured GABAergic hippocampal neurons. GABAergic neurons were identified using an antibody against GABA and the results show a punctated distribution of VGAT along neurites.

\section{Discussion}

In this work, we show that VGAT is cleaved under excitotoxic conditions in vitro and in vivo, and in transient focal cerebral ischemia, giving rise to a truncated product that lacks a punctate synaptic distribution. VGAT cleavage was mediated by calpains, and the stability of the cleavage product suggests that the protease plays a modulatory role rather than a destructive effect in excitotoxic neuronal damage. These findings are in agreement with the key role played by calpains in excitotoxic neuronal damage and in brain ischemia (Bevers and Neumar, 2008).

Several pieces of evidence indicate that calpains mediate VGAT cleavage under excitotoxic conditions, as follows: (1) chemical inhibitors of calpain prevented the formation of a VGAT cleavage product in cultured neurons subjected to excitotoxic stimulation with glutamate; (2) transgenic mice overexpressing calpastatin, the 
endogenous calpain inhibitor, showed a decrease in kainate-evoked VGAT cleavage; (3) incubation of synaptic vesicles with recombinant calpain in the presence of physiological calcium concentrations induces the cleavage of VGAT. Calpains are also activated in the striatum and in the cerebral cortex after MCAO, contributing to neuronal death (Takagaki et al., 1997; Bevers and Neumar, 2008), and may mediate the observed cleavage of VGAT in mice exposed to this model of transient focal brain ischemia. VGAT cleavage in the hippocampus of rats following systemic injection of kainate may also arise from calpain activation. In fact, activation of calpains was shown to contribute to neurodegeneration in the hippocampus in this model of temporal lobe epilepsy (Goodman, 1998; Araújo et al., 2008). Interestingly, 24 h after MCAO there was a recovery of fulllength VGAT protein levels, suggesting that the functional consequences of the cleavage of the transporter may be more relevant in the first hours after ischemia, when excitotoxicity takes place, and alterations in GABAergic synaptic transmission may interfere in the balance excitation/inhibition. VGAT cleavage was also observed under conditions that were previously shown to increase the excitatory activity in cultures of hippocampal neurons, known as chemical LTP, and this effect was also abrogated in the presence of the calpain inhibitor ALLN. The cleavage of VGAT under these conditions was not as significant as under excitotoxic conditions (compare Figs. 1A, 3), most likely due to a controlled activation of calpains. Accordingly, activation of extrasynaptic NMDA receptors was shown to be more efficient in inducing the cleavage of calpain substrates than stimulation of synaptic receptors (Xu et al., 2009). However, the calpain-mediated cleavage of VGAT under conditions leading to long-term changes in synaptic activity correlates with the reported role of calpain in the regulation of synaptic function and memory formation under normal physiological conditions (Liu et al., 2008).

The total VGAT protein levels (full-length + cleaved transporter) in hippocampal neurons subjected to excitotoxic conditions was not changed $12 \mathrm{~h}$ after the insult, suggesting that the cleavage of the transporter represents a posttranslational modification. The truncated form of the transporter was highly stable, being present in cultured hippocampal neurons $24 \mathrm{~h}$ after the excitotoxic insult. In addition to VGAT, calpains cleave other proteins in brain ischemia and under excitotoxic conditions, giving rise to stable cleavage products (Chan and Mattson, 1999; Hou et al., 2006; Cao et al., 2007; Xu et al., 2007; Bevers and Neumar, 2008; Gascón et al., 2008). Excitotoxic stimulation also decreased the mRNA for VGAT, which may prevent de novo synthesis of the transporter to compensate for the loss of the full-length protein in surviving neurons. This loss of VGAT mRNA
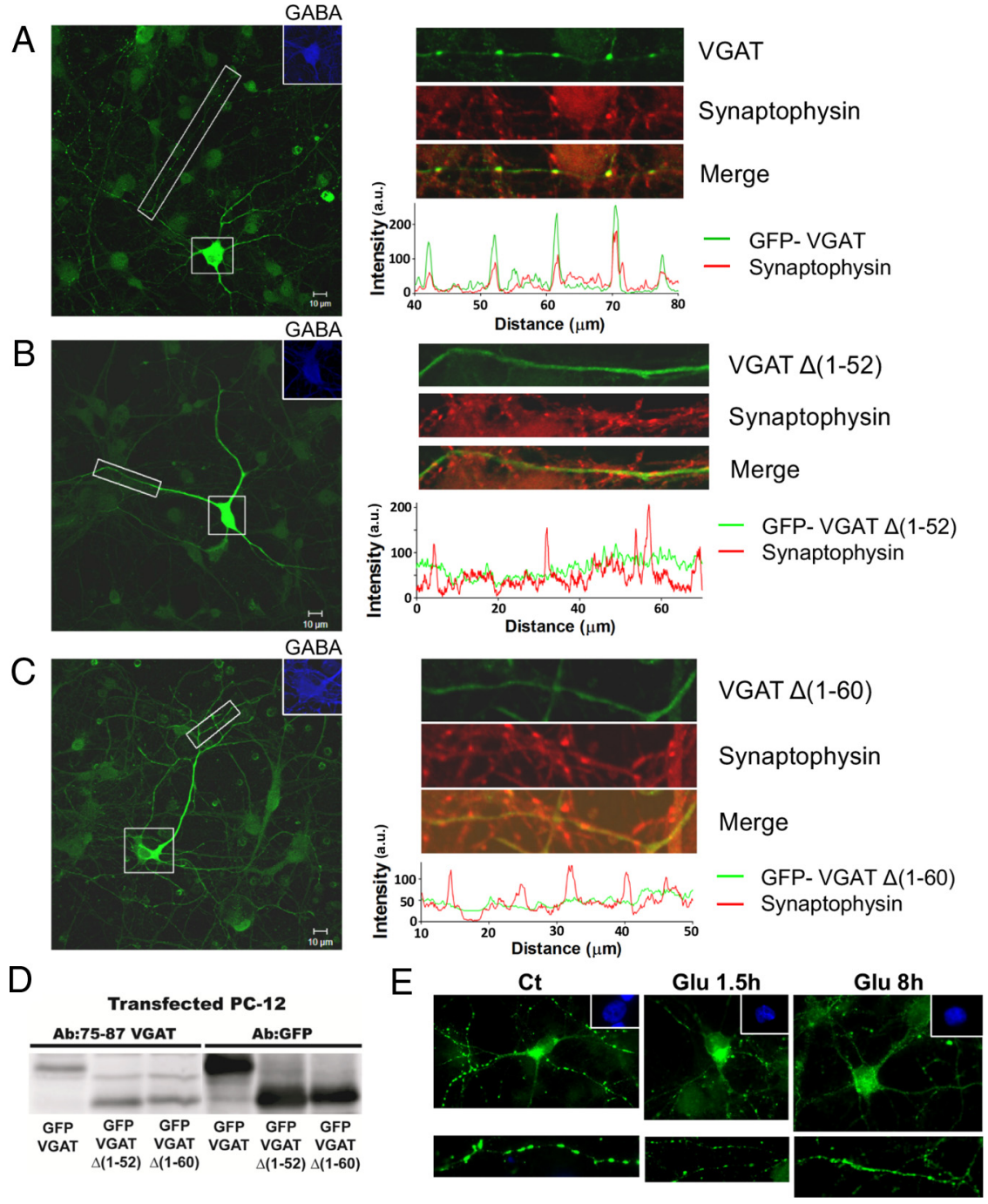

Figure 8. VGAT cleavage changes the distribution of the protein along axons. $\boldsymbol{A}$, Cultured striatal neurons (11 DIV) were transfected with GFP-VGAT $(\boldsymbol{A})$, GFP-VGAT $\Delta(1-52)(\boldsymbol{B})$, or GFP-VGAT $\Delta(1-60)(\boldsymbol{C})$. Fixed and permeabilized cells were incubated with primary antibodies against GFP (green), synaptophysin (red), and GABA (blue). Transfected GABAergic neurons (stained with the antibody against $G A B A)$ are shown on the left $(\boldsymbol{A}-\boldsymbol{C})$ and zoom images of their neurites on the right. The pixel intensities for VGAT [GFP-VGAT $\Delta(1-52)$, GFP-VGAT $\Delta(1-60)$ ] were transfected in PC-12 cells, and cellular extracts were analyzed by Western 列 1.5 or $8 \mathrm{~h}$. After fixation and permeabilization, the cells were incubated with a primary antibody that reacts with the N-terminal region of VGAT (amino acids 75-87) and the nuclear marker Hoechst $33342(0.5 \mu \mathrm{g} / \mathrm{ml})$. VGAT detection was performed with a secondary antibody labeled with Alexa 488.

is likely due to active degradation rather than inhibition of transcription, since transcription inhibition for the same period of time was without effect. A decrease in VGAT mRNA and downregulation of VGAT protein levels was also observed in the cerebral cortex of rats subjected to transient focal cerebral ischemia (Raghavendra Rao et al., 2002; Vemuganti, 2005).

The cleavage of VGAT under excitotoxic conditions was biphasic, consisting in an early calpain-sensitive step followed by a delayed phase $(t=3-8 \mathrm{~h})$, with a lower sensitivity to calpain inhibitors. The first step may be mediated by the $\mu$-calpain isoform, which is activated by calcium at micromolar concentrations. The late VGAT cleavage may be mediated by m-calpains, which require higher calcium concentrations, in the millimolar range (Goll et al., 2003).

Western blot experiments using antibodies against the $\mathrm{N}$ - and C-terminal regions of VGAT showed that the transporter is 


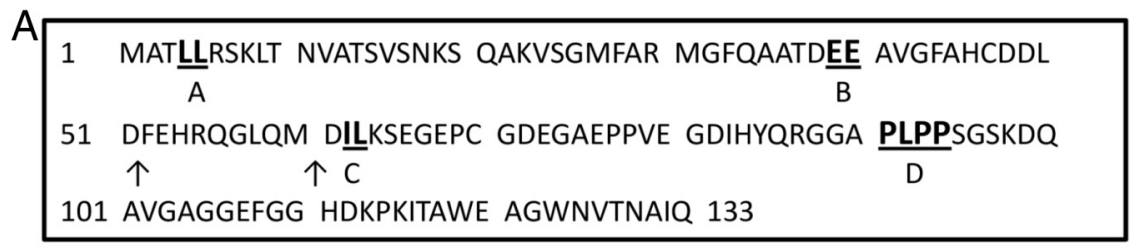

B
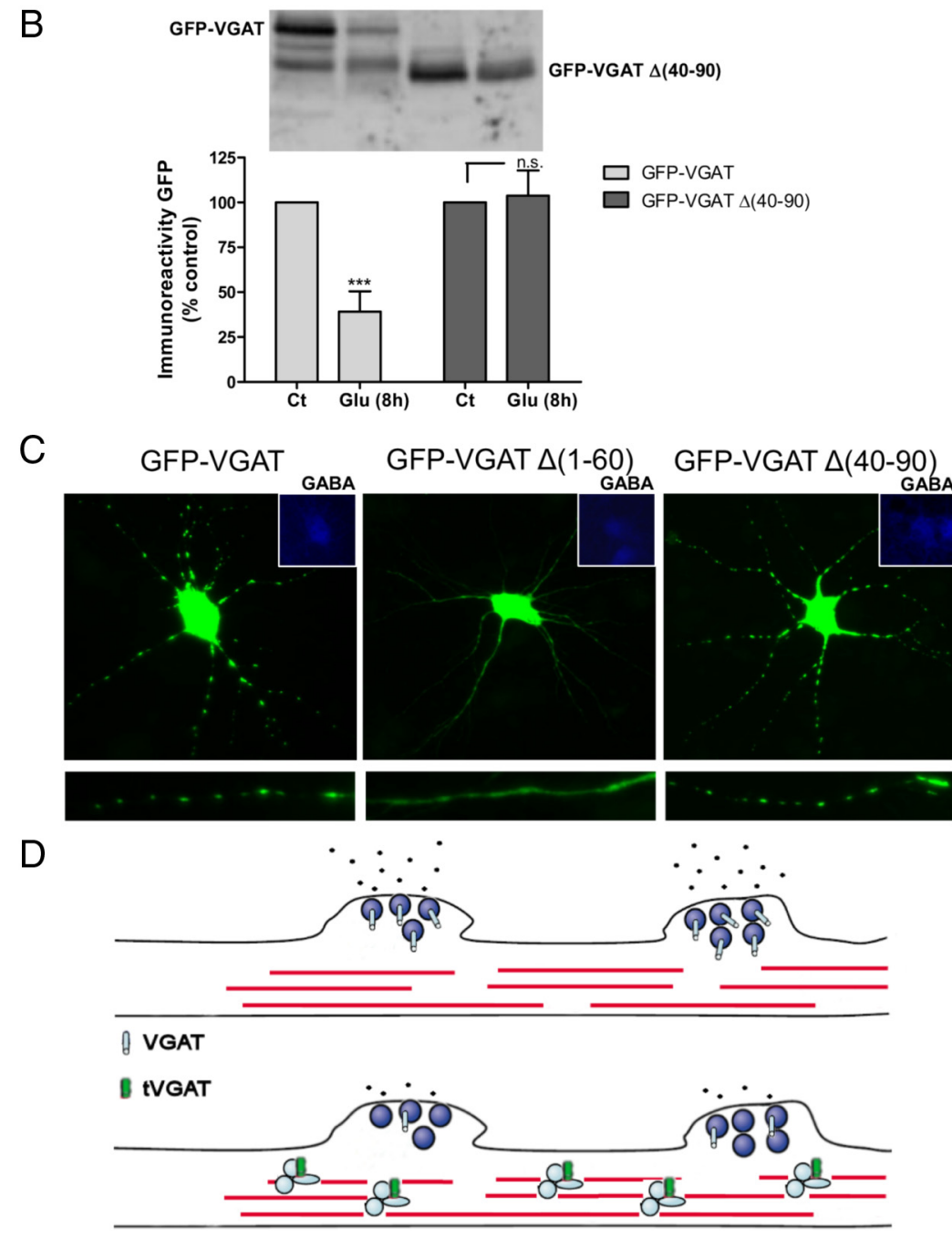

Figure 9. Proposed mechanism of VGAT cleavage and tVGAT formation in the GABAergic synapses. A, Cytoplasmic N-terminal region of VGAT is shown with putative trafficking signals underlined $(\boldsymbol{A}-\boldsymbol{D})$, identified based on the characterization reported for other vesicular transporters. The arrows indicate the calpain cleavage sites described in this work. $\boldsymbol{B}$, Cultured hippocampal neurons (7 DIV) transfected with GFP-VGAT or a mutated form of GFP-VGAT lacking amino acids $40-90$ ( $\Delta 40-90$; the deleted sequence contains the calpain cleavage sites and a PEST sequence) were challenged with glutamate ( $125 \mu \mathrm{M}, 20 \mathrm{~min})$ and further incubated in culture-conditioned medium for $8 \mathrm{~h}$. Excitotoxic stimulation was conducted $72 \mathrm{~h}$ after transfection and the extracts were analyzed by Western blot, using an antibody against GFP. Statistical analysis was performed using the one-way ANOVA followed by Bonferroni's multiple comparison test ${ }^{* * *} p<0.001 ; n$.s., not significant). C, Cultured hippocampal neurons (10 DIV) were transfected with GFP-VGAT, GFP-VGAT $\Delta(1-60)$, and GFP-VGAT $\Delta(40-90)$, and $3-4 \mathrm{~d}$ later the cells were fixed and permeabilized for immunocytochemistry. The cells were incubated with primary antibodies against GFP (green) and GABA (blue). The figure shows transfected GABAergic neurons (stained with the antibody against GABA) expressing the GFP-VGAT forms. The zoom images show the distribution of the transporter along axons and the GABA stained soma (inset). D, Diagram showing the effect of VGAT cleavage on the distribution of the protein along axons. VGAT cleavage at the N-terminal region by calpain may eliminate trafficking signals that determine the subcellular distribution of the protein. Therefore, tVGAT is not accumulated in the vesicles present in synaptic regions. This is likely to affect the amount of GABA stored in synaptic vesicles accumulated at the synapse and may decrease the synaptic release of the neurotransmitter.

cleaved by calpain at the $\mathrm{N}$-terminal region (Fig. $7 B$ ). According to the predicted topology (Fig. 7A), this region is directed toward the cytoplasm, and incubation of calpain with a recombinant GST fusion protein with the N-terminus of VGAT showed two cleavage sites, at amino acids 52 and 60 . This is further supported by the results showing that the truncated VGAT present in hippocampal neurons subjected to excitotoxic stimulation and the truncated VGAT [VGATA(1-52) and (1-60)] expressed in PC12 cells display a similar mobility in SDS-PAGE (Fig. 7G). Analysis of the amino acid sequence of with the $\mathrm{N}$-terminal region of VGAT shows a putative PEST sequence. These sequences are thought to constitute a signal for rapid intracellular proteolysis (Rogers et al., 1986; Rechsteiner and Rogers, 1996) and have been linked to protein cleavage by calpains (Shumway et al., 1999). However, whether PEST sequences provide a signal for cleavage by calpains is still an open issue because mutations of this sequence did not abolish calpain cleavage in some proteins and there are calpain substrates that lack PEST sequences (Carillo et al., 1996). To further evaluate the putative cleavage site(s) in the $\mathrm{N}$-terminal region of VGAT, we used the algorithm of Tompa et al. (2004), which allows predicting amino acid sequences targeted by calpain (Fig. 7C). The sequences near amino acids 52 and 60 in the $\mathrm{N}$-terminal region of VGAT show high scores, characteristic of calpain cleavage sites. Interestingly, the $\mathrm{N}$-terminal region of VGAT is one of the most disordered segments of the protein, and different studies have proposed that calpains cleave their substrates in rather disordered regions (Fontana et al., 1997; Tompa et al., 2004).

The studies using GFP fusion proteins with the full-length VGAT and the truncated transporters (at amino acids 52 and $60)$ showed clear differences in the distribution of the transporters along axons. In contrast with the full-length protein, which showed a typical synaptic punctate distribution, the truncated proteins (lacking amino acids $2-51$ or 2-59) were found along neurites with no colocalization with synaptophysin. Cultured hippocampal neurons subjected to excitotoxic stimulation with glutamate also showed a significant decrease in the punctate distribution of the endogenous VGAT, similarly to the distribution of the truncated transporters. These results show that cleavage of VGAT affects the targeting of the transporter to the synapse and/or its retention at the nerve terminals, which is likely to have an impact on the exocytotic release of GABA. The changes in the distribution of VGAT upon cleavage at the $\mathrm{N}$-terminal region resemble those observed in unc-46 Caenorhabditis elegans mutants (Schuske et al., 2007). UNC-46 is a homolog protein of LAMP (lysosomal associated membrane protein) and is localized at synapses, where it acts as a 
sorting factor that targets vesicular GABA transporters to synaptic vesicles. In the unc-46 mutants the vesicular GABA transporters are diffusely spread along the axon and the mislocalization of the transporters significantly reduces the frequency of GABA currents (Schuske et al., 2007). Based on these findings it is tempting to suggest that VGAT cleavage at the N-terminal region may prevent the interaction with binding partners responsible for targeting the transporters to the synapse, thereby affecting exocytotic GABA release.

The N-terminal region of VGAT contains several amino acid sequences that may play a role in synaptic delivery, which can be predicted based on studies performed for other vesicular neurotransmitter transporters (Fig. 9A). To further address this issue we investigated the cellular distribution of a truncated form of VGAT lacking amino acids 40-90 [GFP-VGAT $\Delta(40-90)$ ], which does not contain the PEST sequence and the identified calpain cleavage sites, but possesses three of the four putative trafficking signals. This truncated transporter was not cleaved in hippocampal neurons subjected to excitotoxic conditions but showed a typical synaptic punctate distribution. These results are in agreement with the calpain cleavage sites identified based on the studies using recombinant calpain and the GST fusion protein with the N-terminal region of VGAT, and suggest that the PEST sequence may be important in the cleavage of the transporter. Furthermore, they suggest that the LL and EE motifs found in the N-terminal region of VGAT are important in the synaptic delivery of the protein.

Together, the results indicate that calpain-mediated VGAT cleavage under excitotoxic conditions gives rise to a truncated form of the transporter lacking sequences responsible for synaptic targeting (Fig. 9D). A similar effect may occur, although to a lower extent, in synapses undergoing high-frequency stimulation. VGAT cleavage by calpain leads to the formation of a new and stable VGAT form, tVGAT, which is not targeted to the synapse. This is expected to decrease the release of GABA by exocytosis, thereby changing the equilibrium between excitatory and inhibitory synaptic activity in the early phases after the excitotoxic insult.

\section{References}

Allen NJ, Rossi DJ, Attwell D (2004) Sequential release of GABA by exocytosis and reversed uptake leads to neuronal swelling in simulated ischemia of hippocampal slices. J Neurosci 24:3837-3849.

Almeida RD, Manadas BJ, Melo CV, Gomes JR, Mendes CS, Grãos MM, Carvalho RF, Carvalho AP, Duarte CB (2005) Neuroprotection by BDNF against glutamate-induced apoptotic cell death is mediated by ERK and PI3-kinase pathways. Cell Death Differ 12:1329-1343.

Araújo IM, Gil JM, Carreira BP, Mohapel P, Petersen A, Pinheiro PS, Soulet D, Bahr BA, Brundin P, Carvalho CM (2008) Calpain activation is involved in early caspase-independent neurodegeneration in the hippocampus following status epilepticus. J Neurochem 105:666-676.

Bedet C, Isambert MF, Henry JP, Gasnier B (2000) Constitutive phosphorylation of the vesicular inhibitory amino acid transporter in rat central nervous system. J Neurochem 75:1654-1663.

Bevers MB, Neumar RW (2008) Mechanistic role of calpains in postischemic neurodegeneration. J Cereb Blood Flow Metab 28:655-673.

Butts BD, Hudson HR, Linseman DA, Le SS, Ryan KR, Bouchard RJ, Heidenreich KA (2005) Proteasome inhibition elicits a biphasic effect on neuronal apoptosis via differential regulation of pro-survival and proapoptotic transcription factors. Mol Cell Neurosci 30:279-289.

Caldeira MV, Melo CV, Pereira DB, Carvalho R, Correia SS, Backos DS, Carvalho AL, Esteban JA, Duarte CB (2007) Brain-derived neurotrophic factor regulates the expression and synaptic delivery of alpha-amino-3-hydroxy-5-methyl-4-isoxazole propionic acid receptor subunits in hippocampal neurons. J Biol Chem 282:12619-12628.

Candiano G, Bruschi M, Musante L, Santucci L, Ghiggeri GM, Carnemolla B,
Orecchia P, Zardi L, Righetti PG (2004) Blue silver: a very sensitive colloidal Coomassie G-250 staining for proteome analysis. Electrophoresis 25:1327-1333.

Cao G, Xing J, Xiao X, Liou AK, Gao Y, Yin XM, Clark RS, Graham SH, Chen J (2007) Critical role of calpain I in mitochondrial release of apoptosisinducing factor in ischemic neuronal injury. J Neurosci 27:9278-9293.

Carillo S, Pariat M, Steff A, Jariel-Encontre I, Poulat F, Berta P, Piechaczyk M (1996) PEST motifs are not required for rapid calpain-mediated proteolysis of c-fos protein. Biochem J 313:245-251.

Chan SL, Mattson MP (1999) Caspase and calpain substrates: roles in synaptic plasticity and cell death. J Neurosci Res 58:167-190.

Chessler SD, Simonson WT, Sweet IR, Hammerle LP (2002) Expression of the vesicular inhibitory amino acid transporter in pancreatic islet cells: distribution of the transporter within rat islets. Diabetes 51:1763-1771.

Dumoulin A, Rostaing P, Bedet C, Lévi S, Isambert MF, Henry JP, Triller A, Gasnier B (1999) Presence of the vesicular inhibitory amino acid transporter in GABAergic and glycinergic synaptic terminal boutons. J Cell Sci 112:811-823.

Ebihara S, Obata K, Yanagawa Y (2003) Mouse vesicular GABA transporter gene: genomic organization, transcriptional regulation and chromosomal localization. Brain Res Mol Brain Res 110:126-139.

Edwards RH (2007) The neurotransmitter cycle and quantal size. Neuron 55:835-858.

Erickson JD, De Gois S, Varoqui H, Schafer MK, Weihe E (2006) Activitydependent regulation of vesicular glutamate and GABA transporters: a means to scale quantal size. Neurochem Int 48:643-649.

Fei H, Grygoruk A, Brooks ES, Chen A, Krantz DE (2008) Trafficking of vesicular neurotransmitter transporters. Traffic 9:1425-1436.

Fontana A, Polverino de Laureto P, De Filippis V, Scaramella E, Zambonin M (1997) Probing the partly folded states of proteins by limited proteolysis. Fold Des 2:R17-R26.

Gascón S, Sobrado M, Roda JM, Rodríguez-Peña A, Díaz-Guerra M (2008) Excitotoxicity and focal cerebral ischemia induce truncation of the NR2A and NR2B subunits of the NMDA receptor and cleavage of the scaffolding protein PSD-95. Mol Psychiatry 13:99-114.

Goll DE, Thompson VF, Li H, Wei W, Cong J (2003) The calpain system. Physiol Rev 83:731-801.

Goodman JH (1998) Experimental models of status epilepticus. In: Neuropharmacology methods in epilepsy research (Peterson SL, ed), pp 95-125. Boca Raton, FL: CRC.

Higuchi M, Tomioka M, Takano J, Shirotani K, Iwata N, Masumoto H, Maki M, Itohara S, Saido TC (2005) Distinct mechanistic roles of calpain and caspase activation in neurodegeneration as revealed in mice overexpressing their specific inhibitors. J Biol Chem 280:15229-15237.

Hou ST, Jiang SX, Desbois A, Huang D, Kelly J, Tessier L, Karchewski L, Kappler J (2006) Calpain-cleaved collapsin response mediator protein-3 induces neuronal death after glutamate toxicity and cerebral ischemia. J Neurosci 26:2241-2249.

Ishida T, Kinoshita K (2008) Prediction of disordered regions in proteins based on the meta approach. Bioinformatics 24:1344-1348.

Jiang M, Deng L, Chen G (2004) High $\mathrm{Ca}^{2+}$-phosphate transfection efficiency enables single neuron gene analysis. Gene Ther 11:1303-1311.

Jourdi H, Lu X, Yanagihara T, Lauterborn JC, Bi X, Gall CM, Baudry M (2005) Prolonged positive modulation of alpha-amino-3-hydroxy-5methyl-4-isoxazolepropionic acid (AMPA) receptors induces calpainmediated PSD-95/Dlg/ZO-1 protein degradation and AMPA receptor down-regulation in cultured hippocampal slices. J Pharmacol Exp Ther 314:16-26.

Kaech S, Banker G (2006) Culturing hippocampal neurons. Nat Protoc 1:2406-2415.

Lima RF, Prado VF, Prado MA, Kushmerick C (2010) Quantal release of acetylcholine in mice with reduced levels of the vesicular acetylcholine transporter. J Neurochem 113:943-951.

Liu J, Liu MC, Wang KK (2008) Calpain in the CNS: from synaptic function to neurotoxicity. Sci Signal 1:tr3.

Martens H, Weston MC, Boulland JL, Grønborg M, Grosche J, Kacza J, Hoffmann A, Matteoli M, Takamori S, Harkany T, Chaudhry FA, Rosenmund C, Erck C, Jahn R, Härtig W (2008) Unique luminal localization of VGAT-C terminus allows for selective labeling of active cortical GABAergic synapses. J Neurosci 28:13125-13131.

McGuigan JA, Kay JW, Elder HY, Lüthi D (2007) Comparison between measured and calculated ionised concentrations in $\mathrm{Mg}^{2+} / \mathrm{ATP}$, 
$\mathrm{Mg}^{2+} /$ EDTA and $\mathrm{Ca}^{2+} /$ EGTA buffers; influence of changes in temperature, $\mathrm{pH}$ and pipetting errors on the ionised concentrations. Magnes Res 20:72-81.

McIntire SL, Reimer RJ, Schuske K, Edwards RH, Jorgensen EM (1997) Identification and characterization of the vesicular GABA transporter. Nature 389:870-876.

Nygren J, Wieloch T (2005) Enriched environment enhances recovery of motor function after focal ischemia in mice, and downregulates the transcription factor NGFI-A. J Cereb Blood Flow Metab 25:1625-1633.

Oh WJ, Noggle SA, Maddox DM, Condie BG (2005) The mouse vesicular inhibitory amino acid transporter gene: expression during embryogenesis, analysis of its core promoter in neural stem cells and a reconsideration of its alternate splicing. Gene 351:39-49.

Patton C, Thompson S, Epel D (2004) Some precautions in using chelators to buffer metals in biological solutions. Cell Calcium 35:427-431.

Pfaffl MW (2001) A new mathematical model for relative quantification in real-time RT-PCR. Nucleic Acids Res 29:e45.

Raghavendra Rao VL, Bowen KK, Dhodda VK, Song G, Franklin JL, Gavva NR, Dempsey RJ (2002) Gene expression analysis of spontaneously hypertensive rat cerebral cortex following transient focal cerebral ischemia. J Neurochem 83:1072-1086.

Rechsteiner M, Rogers SW (1996) PEST sequences and regulation by proteolysis. Trends Biochem Sci 21:267-271.

Rideout HJ, Stefanis L (2002) Proteasomal inhibition-induced inclusion formation and death in cortical neurons require transcription and ubiquitination. Mol Cell Neurosci 21:223-238.

Rogers S, Wells R, Rechsteiner M (1986) Amino acid sequences common to rapidly degraded proteins: the PEST hypothesis. Science 234:364-368.

Santos AR, Duarte CB (2008) Validation of internal control genes for expression studies: effects of the neurotrophin BDNF on hippocampal neurons. J Neurosci Res 86:3684-3692.

Schägger H, von Jagow G (1987) Tricine-sodium dodecyl sulfate-polyacrylamide gel electrophoresis for the separation of proteins in the range from 1 to $100 \mathrm{kDa}$. Anal Biochem 166:368-379.

Schuske K, Palfreyman MT, Watanabe S, Jorgensen EM (2007) UNC-46 is required for trafficking of the vesicular GABA transporter. Nat Neurosci 10:846-853.

Schwartz-Bloom RD, Sah R (2001) gamma-Aminobutyric acid ${ }^{\mathrm{A}}$ neurotransmission and cerebral ischemia. J Neurochem 77:353-371.

Shepherd JD, Rumbaugh G, Wu J, Chowdhury S, Plath N, Kuhl D, Huganir RL, Worley PF (2006) Arc/Arg3.1 mediates homeostatic synaptic scaling of AMPA receptors. Neuron 52:475-484.

Shumway SD, Maki M, Miyamoto S (1999) The PEST domain of IkappaBalpha is necessary and sufficient for in vitro degradation by mu-calpain. J Biol Chem 274:30874-30881.

Silva AP, Xapelli S, Pinheiro PS, Ferreira R, Lourenço J, Cristóvão A, Grouzmann E, Cavadas C, Oliveira CR, Malva JO (2005) Up-regulation of neuropeptide $\mathrm{Y}$ levels and modulation of glutamate release through neuropeptide $\mathrm{Y}$ receptors in the hippocampus of kainate-induced epileptic rats. J Neurochem 93:163-170.

Suckow AT, Sweet IR, Van Yserloo B, Rutledge EA, Hall TR, Waldrop M, Chessler SD (2006) Identification and characterization of a novel isoform of the vesicular gamma-aminobutyric acid transporter with glucoseregulated expression in rat islets. J Mol Endocrinol 36:187-199.
Szydlowska K, Tymianski M (2010) Calcium, ischemia and excitotoxicity. Cell Calcium 47:122-129.

Takagaki Y, Itoh Y, Aoki Y, Ukai Y, Yoshikuni Y, Kimura K (1997) Inhibition of ischemia-induced fodrin breakdown by a novel phenylpyrimidine derivative NS-7: an implication for its neuroprotective action in rats with middle cerebral artery occlusion. J Neurochem 68:2507-2513.

Takamori S, Riedel D, Jahn R (2000) Immunoisolation of GABA-specific synaptic vesicles defines a functionally distinct subset of synaptic vesicles. J Neurosci 20:4904-4911.

Takano J, Tomioka M, Tsubuki S, Higuchi M, Iwata N, Itohara S, Maki M, Saido TC (2005) Calpain mediates excitotoxic DNA fragmentation via mitochondrial pathways in adult brains: evidence from calpastatin mutant mice. J Biol Chem 280:16175-16184.

Tomioka M, Shirotani K, Iwata N, Lee HJ, Yang F, Cole GM, Seyama Y, Saido TC (2002) In vivo role of caspases in excitotoxic neuronal death: generation and analysis of transgenic mice expressing baculoviral caspase inhibitor, p35, in postnatal neurons. Brain Res Mol Brain Res 108:18-32.

Tompa P, Buzder-Lantos P, Tantos A, Farkas A, Szilágyi A, Bánóczi Z, Hudecz F, Friedrich P (2004) On the sequential determinants of calpain cleavage. J Biol Chem 279:20775-20785.

Traystman RJ (2003) Animal models of focal and global cerebral ischemia. ILAR J 44:85-95.

van der Hel WS, Verlinde SA, Meijer DH, de Wit M, Rensen MG, van Gassen KL, van Rijen PC, van Veelen CW, de Graan PN (2009) Hippocampal distribution of vesicular glutamate transporter 1 in patients with temporal lobe epilepsy. Epilepsia 50:1717-1728.

Vemuganti R (2005) Decreased expression of vesicular GABA transporter, but not vesicular glutamate, acetylcholine and monoamine transporters in rat brain following focal ischemia. Neurochem Int 47:136-142.

Vosler PS, Brennan CS, Chen J (2008) Calpain-mediated signaling mechanisms in neuronal injury and neurodegeneration. Mol Neurobiol 38: $78-100$.

Wang Q, Yu S, Simonyi A, Sun GY, Sun AY (2005) Kainic acid-mediated excitotoxicity as a model for neurodegeneration. Mol Neurobiol 31:3-16.

Wilson NR, Kang J, Hueske EV, Leung T, Varoqui H, Murnick JG, Erickson JD, Liu G (2005) Presynaptic regulation of quantal size by the vesicular glutamate transporter VGLUT1. J Neurosci 25:6221-6234.

Wu XS, Xue L, Mohan R, Paradiso K, Gillis KD, Wu LG (2007) The origin of quantal size variation: vesicular glutamate concentration plays a significant role. J Neurosci 27:3046-3056.

Xu J, Kurup P, Zhang Y, Goebel-Goody SM, Wu PH, Hawasli AH, Baum ML, Bibb JA, Lombroso PJ (2009) Extrasynaptic NMDA receptors couple preferentially to excitotoxicity via calpain-mediated cleavage of STEP. J Neurosci 29:9330-9343.

Xu W, Wong TP, Chery N, Gaertner T, Wang YT, Baudry M (2007) Calpain-mediated mGluR1alpha truncation: a key step in excitotoxicity. Neuron 53:399-412.

Yamashima T (2000) Implication of cysteine proteases calpain, cathepsin and caspase in ischemic neuronal death of primates. Prog Neurobiol 62:273-295.

Yuen EY, Liu W, Yan Z (2007) The phosphorylation state of GluR1 subunits determines the susceptibility of AMPA receptors to calpain cleavage. J Biol Chem 282:16434-16440. 